\title{
Discrete-time affine term structure models with macroeconomic factors: Applied to German covered bonds
}

\author{
Polikhronidi, Xeniya \\ Jakas, Vicente \\ - ReCeIVed: 6 OCtober 2014 \\ - ACCEPTED: 7 DeCeMBer 2014
}

\section{Abstract}

In this paper we calibrate the term structure of interest rates of German covered bonds and explain its dynamics in a similar set up to Jakas $(2011,2012)$. However, two approaches to the affine model are employed here: (i) including and (ii) disregarding the no-arbitrage condition. Similar to Jakas $(2011,2012)$ the stochastic discount factor (SDF) accounts for such macroeconomic factors as consumer expectations, unemployment rate, inflation rate and money supply. When including no-arbitrage, the yield curves are calibrated using a discrete time affine multifactor term structure model. Interestingly, when the no-arbitrage condition is disregarded, coefficients can take both positive and negative values along the yield curve, something that does not occur with an affine no-arbitrage model. Overall, the empirical findings in this study confirm the observations in the macrofinance literature, suggesting that macroeconomic factors have a strong explanatory power in the movements of the term structure of interest rates. We also find that the influence of macroeconomic variables is more pronounced at the front end rather than on longer maturities.

\section{Keywords:}

Macroeconomic releases, Term structure of interest rates, Dynamic factors, Affine term structure models.

\section{JEL classification:}

E12, E43, E44, E52, G12.

Polikhronidi, X. is in Credit Risk Management at Deutsche Bank AG for the area of Asset Wealth Management; this work is part of the research she is currently carrying out at Goethe University, Germany, in cooperation with Deutsche Bank AG.

Jakas,V. is in Finance CB\&S Germany at Deutsche Bank AG.Email: vicente.jakas@t-online.de

This work is part of the research he is currently carrying out in cooperation with Saarland University, Germany. All opinions expressed in this paper constitute the authors' own personal ideas and not those of Deutsche Bank AG. 


\title{
Modelos afín discretos de
} estructura temporal de tipos de interés con factores macroeconómicos:

\section{aplicación al mercado de obligaciones alemanas garantizadas}

\author{
Polikhronidi, Xeniya \\ Jakas, Vicente
}

\section{Resumen}

En este artículo se calibra la estructura temporal de tipos de interés de las obligaciones alemanas garantizadas, así como se explica su dinámica en un contexto similar al de Jakas (2011, 2012). Sin embargo, en este artículo se utilizan los dos enfoques de los modelos afines: bajo la condición de no arbitraje y con la violación de esta condición. También, de forma similar a Jakas (2011, 2012), el factor de descuento estocástico da cuenta de factores macroeconómicos tales como las expectativas del consumidor, la tasa de desempleo, la tasa de inflación y la oferta monetaria. En el enfoque de no arbitraje, las curvas de rendimientos se calibran mediante un modelo afín multifactorial de estructura temporal discreto en el tiempo. Curiosamente, cuando se ignora la condición de no arbitraje, los coeficientes del modelo pueden tomar valores positivos y negativos a lo largo de la curva, algo que no es posible reproducir con la condición de no arbitraje afín. En general, los resultados empíricos confirman los de la literatura macrofinanciera en el sentido de que los factores macroeconómicos explican en gran medida los movimientos de la estructura de tipos de interés. De forma similar a la literatura sobre la cuestión, se documenta el hecho de que la influencia de las variables macroeconómicas es más pronunciada en la parte más baja de la curva.

\section{Palabras clave:}

Datos macroeconómicos, estructura temporal de tipos de interés, factores dinámicos, modelos afín de estructura de tipos de interés. 


\section{Introduction}

The purpose of the current study is to calibrate the term structure of the interest rates of German covered bonds and to explain its dynamics using macroeconomic factors in a similar set up to that published in Jakas $(2011,2012)$. To that end, this paper applies the multifactor affine term structure model in discrete time and considers both the arbitrage and no-arbitrage approach. Jakas (2011) provides the basis for the approach in violation of the no-arbitrage condition, where it introduces the following four macroeconomic variables into the model - consumer expectations, unemployment rate, inflation rate, and money supply. Calibration of the yield curves under the no-arbitrage approach in this study relies on multifactor affine term structure models in discrete time - in particular, on the stochastic processes of the Vasicek (1977) and the CIR (1985) described in Backus et al. (1998) and Jakas (2012). German covered bonds - also broadly known as Pfandbriefe - are considered to be among the safest investments and proved to be a stable source of financing during the crisis and in the post-crisis period. As a result, these bonds have been the focus of increasing attention from the market and the regulators. Therefore, this study attempts to contribute not only to the macro-finance literature but also to the developing literature on the German Pfandbriefe, as there is currently limited research on this class of assets from a term structure perspective.

\section{The models}

\section{Case (i): disregarding the no-arbitrage condition with macroeconomic factors}

Despite its economically plausible reasoning, the consumption-based model described by Cochrane (2005) does not perform well empirically (p. 3-45) and different approaches may improve model performance. One of the potential problems may derive from the limited scope of the consumption data (Cochrane, 2005, p. 44) and so Jakas (2011) suggests a model that accounts for four macroeconomic variables. Jakas (2011) used the Consumer Confidence Index $(\mathrm{CCl})$ and unemployment data for the estimation of expected consumption growth in the model, and the Producer Price Index (PPI) for the estimation of the effects of the price level. To account for the effects of changes in the monetary supply, the outstanding amounts of the monetary aggregate M3 was used. While this previous study only represented a regression between money market rates and German government yields with macroeconomic variables, our intention is to test the model with the German Pfandbrief yield curve. Similar to Jakas (2011), an affine term structure model in this paper is expressed by means of a state-space system as:

$$
\begin{gathered}
\mathbf{y}_{t}=\boldsymbol{\beta}_{0}+\boldsymbol{\beta}_{1} \mathbf{z}_{t}+\mathbf{v}_{t}, \\
\mathbf{z}_{t}=\boldsymbol{\alpha} \mathbf{z}_{t-1}+\boldsymbol{\varepsilon}_{t},
\end{gathered}
$$


where,

$\mathbf{y}_{t}: n \times 1$ vector of observed endogenous variables depicting the $n$-yields;

$\boldsymbol{\beta}_{0}: n \times 1$ vector of $n$-coefficients depicting the intercepts;

$\boldsymbol{\beta}_{1}: n \times 4$ matrix of $n$-coefficients for each of the four state variables;

$\mathbf{z}_{t}: 4 \times 1$ vector of observed state variables;

$\mathbf{v}_{t}: n \times 1$ vector of observation-error terms assumed to be i.i.d. ${ }^{1}$;

$\boldsymbol{\varepsilon}_{t}: 4 \times 1$ vector of i.i.d. unobserved state-error terms;

$\boldsymbol{\alpha}: 4 \times 4$ diagonal matrix of coefficients;

Notice that by using equations (1) and (2) arbitrage is possible, as there is no functional specification linking all the parameters with the maturities of the yield curve, as seen in Piazzesi (2010) or Duffie and Kan (1996).

In general, the logic and interpretation of the relationship described by the Jakas (2011) model is similar to the more classical version of consumption-based model described by Cochrane (2005). However, the specification suggested by Jakas (2011) provides an opportunity to analyse interest rate behaviour by considering the effect of a broader scope of different macroeconomic aggregates rather than basing the estimation of the dynamics of an entire economy solely on consumption data. The advantages of this feature of the model will become apparent in section 4 .

\section{Case (ii): including the no-arbitrage condition with macroeconomic factors}

The general framework for affine term structure models (or ATSM) is described in the work of Duffie and Kan (1996). Most term structure models can be regarded as special cases of this broader class of ATSMs, including the Vasicek and the CIR stochastic processes. The ATSM framework of Duffie and Kan (1996) has been adapted to discrete time by Backus et al. (1998), where they base their models on the existence of a unique and positive stochastic discount factor (SDF). To account for the influence of macroeconomic variables on the dynamics of the term structure of interest rates, Jakas (2012) combines the discrete-time set up defined by Backus et al. (1998) with the approach described by Piazzesi (2010) in continuous time. In this paper, the no-arbitrage multifactor ATSMs with macroeconomic factors closely follow the discrete-time specification provided by Jakas (2012).

\section{The Vasicek Multifactor Model}

In discrete time, the 4-dimensional vector of independent state variables $\mathbf{x}_{t+1}$ satisfies the classical stochastic mean-reverting process of the form:

$$
\mathbf{x}_{t+1}=\mathbf{x}_{t}+\boldsymbol{\Phi}\left(\overline{\mathbf{x}}-\mathbf{x}_{t}\right)+\boldsymbol{\sigma}_{x} \boldsymbol{\varepsilon}_{t+1}
$$

\footnotetext{
${ }^{1}$ Independent, identically distributed random variable.
} 
where $\mathbf{x}_{t}$ and $\overline{\mathbf{x}}$ are both 4 -dimensional vectors. $\boldsymbol{\Phi}$ is a $4 \times 4$ diagonal matrix, i.e. $\boldsymbol{\Phi}_{i, i}=$ $\boldsymbol{\Phi}_{i}$, which represents the speed of adjustment at which each of $x_{i, t}$ elements reverse to their means. $\sigma_{x}$ is a diagonal $4 \times 4$ matrix comprising the volatility of the state variables. $\boldsymbol{\varepsilon}_{t+1}$ is a $(4 \times 1)$-vector of shocks moving $\mathbf{x}_{t}$ away from $\overline{\mathbf{x}}$ and with $\varepsilon_{i, t+1}$ elements being normally distributed with mean zero and variance unity.

Following Backus et al. (1998), Jakas (2012) adopts the general specification of the pricing kernel $m_{t+1}$ and adjusts it to the multifactor version with 4-dimensional vector of state variables:

$$
-\ln \left[m_{t+1}\right]=\delta+y_{t}^{(1)}+\lambda^{\prime} \boldsymbol{\varepsilon}_{t+1}
$$

In order to normalize the discount factor to the inverse of the short rate, $\delta$ is specified as follows,

$$
\delta=\frac{1}{2}\left(\sum_{i=1}^{3} \lambda_{i}^{2}\right)
$$

Backus et al. (1998) refer to $\lambda$ - which comprises here the elements $\left(\lambda_{1}, \lambda_{2}, \lambda_{3}, \lambda_{4}\right)-$ as the price of risk, since this parameter governs the covariance of shocks stemming from macroeconomic variables to $m_{t+1}$ and $y_{t}^{(1)}$ in the equation (4). In a similar fashion to Piazzesi (2010) and Cochrane (2005), Jakas (2012) specifies the short-rate $y_{t}^{(1)}$ as $y_{t+1}^{(1)}=a_{0}+\mathbf{a}_{1}^{\prime} \mathbf{x}_{t+1}$ with $a_{0}$ being a constant scalar and $\mathbf{a}_{1}^{\prime}$ being a $1 \times 4$ vector of coefficients multiplying the $4 \times 1$ state vector $\mathbf{x}_{t+1}$. The SDF is assumed to be conditionally log-normally distributed, thereby ensuring a positive discount factor and tractability of solutions. Jakas (2012) suggests the following pricing relationship:

$$
-E\left[\ln P_{t}^{(\mathrm{N}+1)}\right]=\frac{1}{2} \sum_{i=1}^{3} \lambda_{i}^{2}+A(N)+\mathbf{B}(N)^{\prime} \boldsymbol{\Phi} \overline{\mathbf{x}}+\left[\mathbf{a}_{1}^{\prime}+\mathbf{B}(N)^{\prime}(\mathbf{I}-\boldsymbol{\Phi})\right] \mathbf{x}_{t}-\frac{1}{2}\left(\boldsymbol{\lambda}^{\prime}+\mathbf{B}(N)^{\prime} \boldsymbol{\sigma}_{x}\right)^{2}
$$

which, accordingly, is characterized by the coefficients of the form²:

$$
\begin{gathered}
A(N+1)=A(N)+\mathbf{B}(N)^{\prime} \boldsymbol{\Phi} \overline{\mathbf{x}}+\frac{1}{2}\left(\sum_{i=1}^{3} \lambda_{i}^{2}-\left[\boldsymbol{\lambda}^{\prime}+\mathbf{B}(N)^{\prime} \boldsymbol{\sigma}_{x}\right]^{2}\right), \\
\mathbf{B}(N+1)^{\prime}=\mathbf{a}_{1}^{\prime}+\mathbf{B}(N)^{\prime}(\mathbf{I}-\boldsymbol{\Phi}) .
\end{gathered}
$$

The curve is fitted to the observed yields by substituting the coefficients (6) and (7) into:

$$
y_{t}^{(N)}=\frac{\mathbf{A}(N)}{N}+\frac{\mathbf{B}(N)^{\prime}}{N} \mathbf{x}_{t}
$$

and solving numerically in MATLAB by adjusting $\boldsymbol{\lambda}$. The parameters $a_{0}, \mathbf{a}_{1}^{\prime}, \boldsymbol{\Phi}$ and $\boldsymbol{\sigma}_{x}$ are the observed properties of the input data. EONIA is the short rate and, therefore,

\footnotetext{
${ }^{2}$ Details about the algebra can be found in Jakas (2012) or Backus, Foresi and Telmer (1998).
} 
the $a_{0}$ and $\mathbf{a}_{1}^{\prime}$ coefficients are obtained from the observed relationship of EONIA rates with the macroeconomic variables.

\section{The Multifactor CIR Model}

Jakas (2012) takes a similar approach to obtain the coefficients for the CIR Model, where the process for the vector of state variables is specified as follows:

$$
\mathbf{x}_{t+1}=\mathbf{x}_{t}+\boldsymbol{\Phi}\left(\overline{\mathbf{x}}-\mathbf{x}_{t}\right)+\boldsymbol{\sigma}_{x} \sqrt{\mathbf{x}_{t}} \boldsymbol{\varepsilon}_{t+1}
$$

and defines the pricing kernel by:

$$
-\ln \left[m_{t+1}\right]=\left(1+\frac{1}{2} \sum_{i=1}^{4} \lambda_{i}^{2}\right) y_{t}^{(1)}+\lambda \sqrt{\mathbf{x}_{t}} \boldsymbol{\varepsilon}_{t+1}
$$

Equation (10) suggests the following pricing equation, which can be also solved recursively:

$$
\begin{gathered}
-E\left[\ln P_{t}^{(N+1)}\right]=a_{0}\left(1+\frac{1}{2} \sum_{i=1}^{3} \lambda_{i}^{2}\right)+A(N)+\mathbf{B}(N)^{\prime} \mathbf{\Phi} \overline{\mathbf{x}}+ \\
{\left[\left(1+\frac{1}{2} \sum_{i=1}^{3} \lambda_{i}^{2}\right) \mathbf{a}_{1}^{\prime}+\mathbf{B}(N)^{\prime}(\mathbf{I}-\boldsymbol{\Phi})\right] \mathbf{x}_{t}-\frac{1}{2}\left(\boldsymbol{\lambda}^{\prime}+\mathbf{B}(N)^{\prime} \boldsymbol{\sigma}_{x}\right)^{2} \mathbf{x}_{t},}
\end{gathered}
$$

where the coefficients are given by ${ }^{3}$ :

$$
\begin{gathered}
A(N+1)=a_{0}\left(1+\frac{1}{2} \sum_{i=1}^{3} \lambda_{i}^{2}\right)+A(N)+\mathbf{B}(N)^{\prime} \boldsymbol{\Phi} \overline{\mathbf{x}}, \\
\mathbf{B}(N+1)^{\prime}=\left[\left(1+\frac{1}{2} \sum_{i=1}^{3} \lambda_{i}^{2}\right) \mathbf{a}_{1}^{\prime}+\mathbf{B}(N)^{\prime}(\mathbf{I}-\boldsymbol{\Phi})\right]-\frac{1}{2}\left(\boldsymbol{\lambda}+\mathbf{B}(N)^{\prime} \mathbf{\sigma}_{x}\right)^{2} .
\end{gathered}
$$

Similar to the Vasicek case, the multifactor CIR model is solved numerically in MAT$L A B$ by adjusting the price of risk encapsulated in $\boldsymbol{\lambda}$, while other parameters are given by the properties of the observed data.

\section{Data description}

\section{Macroeconomic variables}

Table 1 provides an overview of the data series used for the macroeconomic factors. These series represent monthly data of selected Eurozone's key macroeconomic indicators - Consumer Confidence Index, unemployment rate, Producer Price Index, and Monetary Aggregate M3. In this paper, the choice of the macroeconomic variables has been slightly altered and we use the $\mathrm{M} 3$ index annual growth rates instead of the level.

\footnotetext{
${ }_{3}^{3}$ Details about the algebra can be found in Jakas (2012) or Backus et al. (1998).
} 
Table 1. Macroeconomic variables. Data overview

\begin{tabular}{lccc}
\hline Macroeconomic variables & Measure & Region & Source \\
\hline Real activity measure / Expected consumption & CCI & Eurozone 17 & European Commission Eurostat \\
\hline Real activity measure / Expected consumption & Unemployment & Eurozone 17 & European Commission Eurostat \\
\hline Inflation & PPI & Eurozone 17 & European Commission Eurostat \\
\hline \multirow{2}{*}{ Monetary aggregate } & M3 outst. amounts & Eurozone 17 & European Central Bank \\
\cline { 2 - 4 } & M3 ann. growth rates & Eurozone 17 & European Central Bank \\
\hline
\end{tabular}

The rationale behind this modification in the data is explained in the following paragraphs.

This paper uses the time series of the money growth rate in the economy to estimate the effects of the monetary policy on the term structure. That is, this analysis includes the annual growth rates of the monetary aggregate $\mathrm{M} 3$, which are calculated using the chain index ${ }^{4}$ of notional stocks. These data series allow us to capture movements in monetary dynamics, free from non-transaction effects, which could have a significant effect on the growth rates of stocks (ECB, 2014). For example, the M3 index growth rates are not affected by the changes driven by various types of reclassifications (Hofmann, 2008, p. 11-12). Instead, these data series capture only the changes in the financial flows, such as those resulting from the creation, liquidation, or sale of ownership. On the contrary, the data for M3 outstanding amounts is affected by reclassifications and also accounts for events such as Eurozone enlargement (Fisher et al., 2006, p. 52). Thus, the M3 index growth rate is expected to provide a more accurate estimate of the monetary policy effects on the term structure of interest rates. Furthermore, the ECB itself refers to the changes in the M3 monetary aggregate index as the major indicator for medium- and long-term price stability (ECB, 2011). As part of its two-pillar monetary policy strategy, the ECB set the M3 index growth rate to a $4.5 \%$ per annum reference value ${ }^{5}$, advocating the prominent role of this indicator in the monetary policy analysis (ECB, 1998a,b). Indeed, many financial newspapers, analysts and policy makers refer today to the M3 index growth rate as one of the major macroeconomic indicators for the European economy ${ }^{6}$. Therefore, the primary analysis of this study refers to the latter data series.

For the estimation of inflation effects on interest rate movements this study takes a similar approach to Jakas $(2011,2012)$ in using the monthly industrial Producer Price Index (PPI) data. This is one of the principle European economic indicators set by the European Commission (Eurostat, 2012, p. 5). PPI captures the dynamics in producer prices and

\footnotetext{
${ }^{4}$ Computed as $I_{t}=I_{t-1}\left(1+F_{t} / L_{t-1}\right)$, where $F_{t}$ are transactions in the current period and $L_{t-1}$ are stocks at the end of the previous period (ECB, 20/4).

${ }^{5}$ There have been discussions in the literature about the redundancy of a specific reference value for M3 growth rate. Such discussion lies beyond the scope of this paper. For further details see, for example, Svensson (2000) and Gali (2010).

${ }^{6}$ For more detailed discussion of the role of M3 growth rate as a macroeconomic indicator see, for example, Klöckers and Willeke (200I) or Hofmann (2008).
} 
can thus be considered as an early indicator of inflationary trends, as it can capture price changes before they reach the retail or wholesale levels (Eurostat, 2012, p. 12). For the estimation of the impact of the real activity and expected consumption on the term structure of interest rates, this study also follows the approach of Jakas $(2011,2012)$ and relies on the Eurozone unemployment rate and the Consumer Confidence Index ( $\mathrm{CCl})$. $\mathrm{CCl}$ is a measurement of the economic confidence of consumers for the next 12 months, based on surveys which refer to the overall economic conditions, unemployment expectations, financial situation of households, and savings (European Commission, 2014, p. 12). CCl captures consumer opinion on expected economic developments and represents the cyclical patterns of household consumption quite accurately (Economic Commission for Europe, 2014, p. 11).

\section{Yields}

Table 2 provides an overview of the yields' data series that are considered in this study for the analyses of the term structure of the German covered bonds or so-called Pfandbriefs. All three data sets report the monthly average yields for the covered bonds issued in Germany. However, the accessible sample periods and the length of available maturities differ across the sets. The PEX Bloomberg data include the lowest number of observations and only start at the end of 2003, while the PEX VDP and PEX Bundesbank series cover a longer period and, as a result, include a considerably larger number of observations. The PEX Bloomberg data does however offer observations for the yields of longer maturities extending up to 20 years, while the PEX VDP and PEX Bundesbank series cover maturities for up to 10 and 15 years only, respectively. Hence, to account for the possible influences of these differences across the available data sets and to assess the stability of the performance of the models, all three data sets are separately considered in the analysis. This approach also allows us to uncover possible inconsistencies in the results, which might be driven by the differences in the measurement approaches ${ }^{7}$ or simply by data entry errors. The main results section focuses primarily on the data from Bloomberg as it allows us to model the term structure of interest rates with longer maturities. The results for the other two data sets are briefly presented and summarized in the other results section. The following section describes only the PEX Bloomberg data used for the main findings, and the details for the PEX VDP and PEX Bundesbank data series are not reported here.

\section{Table 2. German covered bonds. Data overview}

\begin{tabular}{lcccccc}
\hline Yields & \multicolumn{1}{c}{ Title } & $\begin{array}{c}\text { Maturities } \\
\text { (Years) }\end{array}$ & Period & Obs. & Region & Source \\
\hline \multirow{2}{*}{$\begin{array}{c}\text { German } \\
\text { covered } \\
\text { bonds }\end{array}$} & PEX Vloomberg & $1-10,15,20$ & Nov 2003-Sep 2012 & 107 & Germany & Bloomberg \\
\cline { 2 - 6 } & PEX Bundesbank & $1-15$ & Jan 2000-Dec 2013 & 168 & Germany & Deutsche Bundesbank \\
\hline
\end{tabular}

${ }^{7}$ For example, yields in the PEX Bundesbank data set are estimated using the Svensson (1994) smoothing technique. 
The PEX Bloomberg data set provides observations for the yields of covered bonds with maturities of $1,2,3,4,5,6,7,8,9,10,15$ and 20 years. Following the approach commonly seen in the term structure literature, the money market rates - Euro Overnight Index Average (EONIA), as well as 3 - and 6-month Euro Interbank Offered Rates (Euribor) - are taken as proxies for the lower end of the yield curve. Generally, the yield data is characterized by a number of commonly observed stylized facts, and the descriptive statistics for the general patterns are summarized in Table 3 and Table 4. On average, the covered bonds yields are an increasing function of maturity, while the yield volatilities, given by the standard deviations, tend to decrease with maturity. The yields are persistent and characterized by high levels of autocorrelation, which decreases for the yields of longer maturities. The skewness and kurtosis across the time series suggest that the data do not follow Gaussian distributions. The fact that yields tend to move together is apparent from the correlation statistics presented in Table 4. The pair-wise correlations are close to perfect for the adjacent maturities and decrease as the maturities become farther apart from each other. These strong correlations indicate that certain common factors exist that drive the curve. However, in general, all correlations are smaller than one. That is, the importance of the non-parallel shifts cannot be ignored in the analysis of the term structure of interest rates.

Table 3. Summary statistics. PEX Bloomberg. German covered bond yields

\begin{tabular}{lcccccccc}
\hline & Mean & SD & Variance & Skewness & Kurtosis & Min & Max & $\begin{array}{c}\text { Autocorr. } \\
(\mathbf{1})\end{array}$ \\
\hline EONIA & 1.937 & 1.341 & 1.799 & 0.292 & 1.766 & 0.100 & 4.300 & 0.992 \\
\hline Euribor 3M & 2.310 & 1.390 & 1.933 & 0.567 & 2.139 & 0.250 & 5.110 & 0.991 \\
\hline Euribor 6M & 2.461 & 1.328 & 1.762 & 0.655 & 2.200 & 0.480 & 5.220 & 0.990 \\
\hline Y1 & 2.441 & 1.363 & 1.858 & 0.428 & 2.017 & 0.250 & 5.280 & 0.990 \\
\hline Y2 & 2.646 & 1.216 & 1.479 & 0.229 & 2.089 & 0.390 & 5.280 & 0.987 \\
\hline Y3 & 2.855 & 1.106 & 1.223 & 0.027 & 2.246 & 0.550 & 5.200 & 0.985 \\
\hline Y4 & 3.052 & 1.000 & 1.000 & -0.143 & 2.437 & 0.810 & 5.110 & 0.983 \\
\hline Y5 & 3.224 & 0.914 & 0.835 & -0.258 & 2.545 & 1.080 & 5.040 & 0.982 \\
\hline Y6 & 3.361 & 0.853 & 0.728 & -0.370 & 2.617 & 1.320 & 5.000 & 0.981 \\
\hline Y7 & 3.482 & 0.804 & 0.647 & -0.460 & 2.667 & 1.530 & 4.980 & 0.979 \\
\hline
\end{tabular}

Data: PEX Bloomberg Monthly Average. Period: November 2003 - September 2012. 
Table 4. Correlations. PEX Bloomberg. German covered bond yields

\begin{tabular}{|c|c|c|c|c|c|c|c|c|c|c|c|c|c|c|c|}
\hline & EONIA & $\begin{array}{r}\text { Euribor } \\
3 \mathrm{M}\end{array}$ & $\begin{array}{r}\text { Euribor } \\
6 \mathrm{M}\end{array}$ & Y1 & Y2 & Y3 & Y4 & Y5 & Y6 & Y7 & Y8 & Y9 & Y10 & Y15 & Y20 \\
\hline EONIA & 1 & & & & & & & & & & & & & & \\
\hline Euribor 3M & 0.9818 & 1 & & & & & & & & & & & & & \\
\hline Euribor $6 \mathrm{M}$ & 0.9745 & 0.9982 & 1 & & & & & & & & & & & & \\
\hline Y1 & 0.9847 & 0.9868 & 0.9866 & 1 & & & & & & & & & & & \\
\hline Y2 & 0.965 & 0.958 & 0.9572 & 0.9871 & 1 & & & & & & & & & & \\
\hline Y3 & 0.9396 & 0.9308 & 0.9289 & 0.966 & 0.994 & 1 & & & & & & & & & \\
\hline Y4 & 0.9105 & 0.9014 & 0.899 & 0.9405 & 0.9798 & 0.9957 & 1 & & & & & & & & \\
\hline Y5 & 0.8859 & 0.8771 & 0.8739 & 0.9173 & 0.9641 & 0.987 & 0.9974 & 1 & & & & & & & \\
\hline Y6 & 0.862 & 0.8527 & 0.8482 & 0.8933 & 0.9461 & 0.9751 & 0.9909 & 0.9979 & 1 & & & & & & \\
\hline Y7 & 0.8379 & 0.8282 & 0.8225 & 0.8689 & 0.9269 & 0.9611 & 0.9816 & 0.9925 & 0.9983 & 1 & & & & & \\
\hline Y8 & 0.8129 & 0.8028 & 0.7959 & 0.8437 & 0.9061 & 0.9452 & 0.9699 & 0.9844 & 0.9937 & 0.9985 & 1 & & & & \\
\hline Y9 & 0.7927 & 0.7824 & 0.7746 & 0.8229 & 0.8885 & 0.931 & 0.9588 & 0.9761 & 0.988 & 0.9953 & 0.9991 & 1 & & & \\
\hline Y10 & 0.7736 & 0.764 & 0.7554 & 0.8037 & 0.8716 & 0.9171 & 0.9476 & 0.9673 & 0.9816 & 0.9909 & 0.9967 & 0.9992 & 1 & & \\
\hline Y15 & 0.7053 & 0.6924 & 0.6818 & 0.7331 & 0.8083 & 0.863 & 0.9028 & 0.9296 & 0.9509 & 0.9665 & 0.9783 & 0.9856 & 0.9904 & 1 & \\
\hline Y20 & 0.6822 & 0.6571 & 0.643 & 0.7015 & 0.7818 & 0.8393 & 0.8812 & 0.9097 & 0.9333 & 0.951 & 0.9648 & 0.9736 & 0.9797 & 0.9956 & 1 \\
\hline
\end{tabular}

Data: PEX Bloomberg, Monthly Average. Period: November 2003 - September 2012.

\section{Discussion of results}

\section{Results obtained disregarding the no-arbitrage condition}

The results in this section are obtained using the model specified in equations (1) and (2). Observations for the yields of covered bonds are taken from the PEX Bloomberg data set. The following four sets of monthly macroeconomic data series are used to estimate the influence of macroeconomic factors on the dynamics of the term structure: (a) $\mathrm{CCl}$; (b) unemployment rate; (3) M3 index annual growth rate; and (4) PPI. Each data set contains 107 observations for the period ranging from November 2003 to September 2012. The results are obtained running a robust OLS regression for the equation (1) in Stata 12. The results that were obtained in the state-space framework for the equations (1) and (2), using SSPACE command in Stata 12, are summarized in the Appendix.

Our main findings are presented in Table 5. In line with previously published results, the present results clearly suggest that a strong relationship exists between the term structure of interest rates and the macroeconomic environment. Almost all coefficients are statistically significant and have low standard errors. The values of $R^{2}$ and adjusted- 
$R^{2}$ are high and decrease with maturity. Figure 1 shows the series of the estimated and observed values for the yields of different maturities. From this plot we clearly see that the model fits remarkably well the observed yields of short- and medium-term maturities, but less well those of longer maturities. Figure 2 illustrates the calculated coefficients against maturities and clearly shows that most of the coefficients are in line with predictions of economic theory. Overall, the four plots on this figure show that the obtained factor-loadings reveal a statistically significant and economically meaningful relationship between the interest rates and the chosen macroeconomic variables.

Table 5. PEX Bloomberg German covered bonds yields data. Robust OLS regression. Model with M3 Ann. Growth rates

\begin{tabular}{|c|c|c|c|c|c|c|c|c|c|c|c|c|c|c|c|}
\hline & EONIA & $\begin{array}{r}\text { Euribor } \\
3 \mathrm{M}\end{array}$ & $\begin{array}{r}\text { Euribor } \\
6 \mathrm{M}\end{array}$ & Y1 & Y2 & Y3 & Y4 & Y5 & Y6 & Y7 & Y8 & Y9 & Y10 & Y15 & Y2O \\
\hline & Coeff. & Coeff. & Coeff. & Coeff. & Coeff. & Coeff. & Coeff. & Coeff. & Coeff. & Coeff. & Coeff. & Coeff. & Coeff. & Coeff. & Coeff. \\
\hline & SE & SE & SE & SE & SE & SE & SE & SE & SE & SE & SE & SE & SE & SE & SE \\
\hline & t-stat & t-stat & t-stat & $t$-stat & $t$-stat & t-stat & t-stat & t-stat & t-stat & t-stat & t-stat & t-stat & t-stat & t-stat & $t$-stat \\
\hline \multirow[t]{3}{*}{ Intercept } & 16.42 & 5.39 & 1.86 & 12.18 & 20.27 & 24.82 & 27.08 & 27.52 & 28.22 & 28.68 & 29.21 & 29.34 & 29.29 & 30.73 & 33.96 \\
\hline & 1.75 & 1.94 & 1.87 & 1.59 & 1.72 & 1.94 & 2.06 & 2.14 & 2.18 & 2.20 & 2.22 & 2.23 & 2.25 & 2.39 & 2.45 \\
\hline & 9.41 & 2.78 & 0.99 & 7.64 & 11.76 & 12.81 & 13.12 & 12.83 & 12.96 & 13.05 & 13.16 & 13.15 & 13.01 & 12.88 & 13.85 \\
\hline \multirow[t]{3}{*}{ Log CCI } & 0.08 & 0.05 & 0.05 & 0.06 & 0.03 & 0.01 & 0.00 & -0.01 & -0.02 & -0.03 & -0.03 & -0.04 & -0.04 & -0.04 & -0.04 \\
\hline & 0.03 & 0.01 & 0.01 & 0.02 & 0.02 & 0.01 & 0.01 & 0.01 & 0.01 & 0.01 & 0.01 & 0.02 & 0.02 & 0.02 & 0.01 \\
\hline & 3.22 & 4.40 & 4.25 & 2.76 & 1.99 & 1.02 & -0.48 & -2.29 & -2.59 & -2.60 & -2.61 & -2.64 & -2.57 & -2.74 & -2.92 \\
\hline \multirow[t]{3}{*}{ Log Unemployment } & -8.65 & -9.67 & -9.45 & -9.71 & -8.79 & -8.17 & -7.56 & -6.91 & -6.42 & -5.99 & -5.66 & -5.39 & -5.16 & -4.70 & -4.47 \\
\hline & 0.27 & 0.30 & 0.30 & 0.33 & 0.36 & 0.37 & 0.36 & 0.35 & 0.34 & 0.33 & 0.32 & 0.31 & 0.31 & 0.31 & 0.31 \\
\hline & -32.16 & -32.68 & -31.49 & -29.47 & -24.65 & -22.27 & -20.78 & -19.50 & -18.86 & -18.22 & -17.64 & -17.11 & -16.56 & -15.33 & -14.52 \\
\hline \multirow[t]{3}{*}{ Log M3 ann. growth } & 0.27 & 0.25 & 0.21 & 0.19 & 0.12 & 0.05 & -0.01 & -0.04 & -0.06 & -0.07 & -0.08 & -0.09 & -0.09 & -0.14 & -0.14 \\
\hline & 0.03 & 0.02 & 0.02 & 0.02 & 0.02 & 0.02 & 0.03 & 0.03 & 0.03 & 0.03 & 0.03 & 0.03 & 0.03 & 0.04 & 0.04 \\
\hline & 10.22 & 11.92 & 11.78 & 9.60 & 7.34 & 2.01 & -0.50 & -1.27 & -1.79 & -2.16 & -2.51 & -2.67 & -2.80 & -3.91 & -3.67 \\
\hline \multirow[t]{3}{*}{ Log PPI } & 0.87 & 3.88 & 4.59 & 2.46 & 0.33 & -0.88 & -1.60 & -1.96 & -2.31 & -2.58 & -2.82 & -2.96 & -3.04 & -3.51 & -4.31 \\
\hline & 0.39 & 0.47 & 0.47 & 0.44 & 0.49 & 0.51 & 0.52 & 0.52 & 0.52 & 0.52 & 0.52 & 0.52 & 0.52 & 0.55 & 0.56 \\
\hline & 2.25 & 8.29 & 9.87 & 5.53 & 0.67 & -1.73 & -3.09 & -3.76 & -4.44 & -4.97 & -5.42 & -5.70 & -5.83 & -6.42 & -7.70 \\
\hline Average Yields & 1.94 & 2.31 & 2.46 & 2.44 & 2.65 & 2.86 & 3.05 & 3.22 & 3.36 & 3.48 & 3.59 & 3.68 & 3.76 & 4.01 & 4.09 \\
\hline Standard Deviation & 1.34 & 1.39 & 1.33 & 1.36 & 1.22 & 1.11 & 1.00 & 0.91 & 0.85 & 0.80 & 0.77 & 0.74 & 0.71 & 0.66 & 0.67 \\
\hline Jarque Bera Test & 33.59 & 11.81 & 11.57 & 14.35 & 9.88 & 5.11 & 2.38 & 2.30 & 3.22 & 4.36 & 5.29 & 5.89 & 6.36 & 8.04 & 8.59 \\
\hline $\mathrm{R}^{2}$ & 0.95 & 0.96 & 0.96 & 0.96 & 0.95 & 0.93 & 0.91 & 0.89 & 0.87 & 0.85 & 0.83 & 0.82 & 0.80 & 0.75 & 0.75 \\
\hline $\mathrm{R}^{2}$ Adjusted & 0.95 & 0.96 & 0.95 & 0.96 & 0.95 & 0.93 & 0.91 & 0.89 & 0.87 & 0.85 & 0.83 & 0.81 & 0.79 & 0.74 & 0.74 \\
\hline DW Statistic & 0.59 & 0.42 & 0.43 & 0.56 & 0.53 & 0.44 & 0.38 & 0.35 & 0.32 & 0.31 & 0.30 & 0.30 & 0.31 & 0.28 & 0.27 \\
\hline Test for ARCH effects & 56.79 & 38.01 & 42.88 & 40.02 & 33.78 & 34.01 & 34.30 & 35.01 & 36.64 & 39.10 & 42.41 & 44.51 & 46.13 & 50.83 & 50.14 \\
\hline
\end{tabular}

Data: PEX Bloomberg, Monthly Average. Observations: 107. Period: November 2003 - September 2012. Estimation Method: OLS Regression, Robust. Note:The Jarque Bera tests reject the null hypothesis of the normal distribution for the yields. The Durbin-Watson statistics are well below the value of 2, indicating a positive first-order autocorrelation in the residuals. The tests for ARCH effects reject the null hypothesis that there is no autoregressive conditional heteroskedasticity in the residuals. For most of the maturities, the DickeyFuller test cannot reject the null hypothesis of a unit root process. 


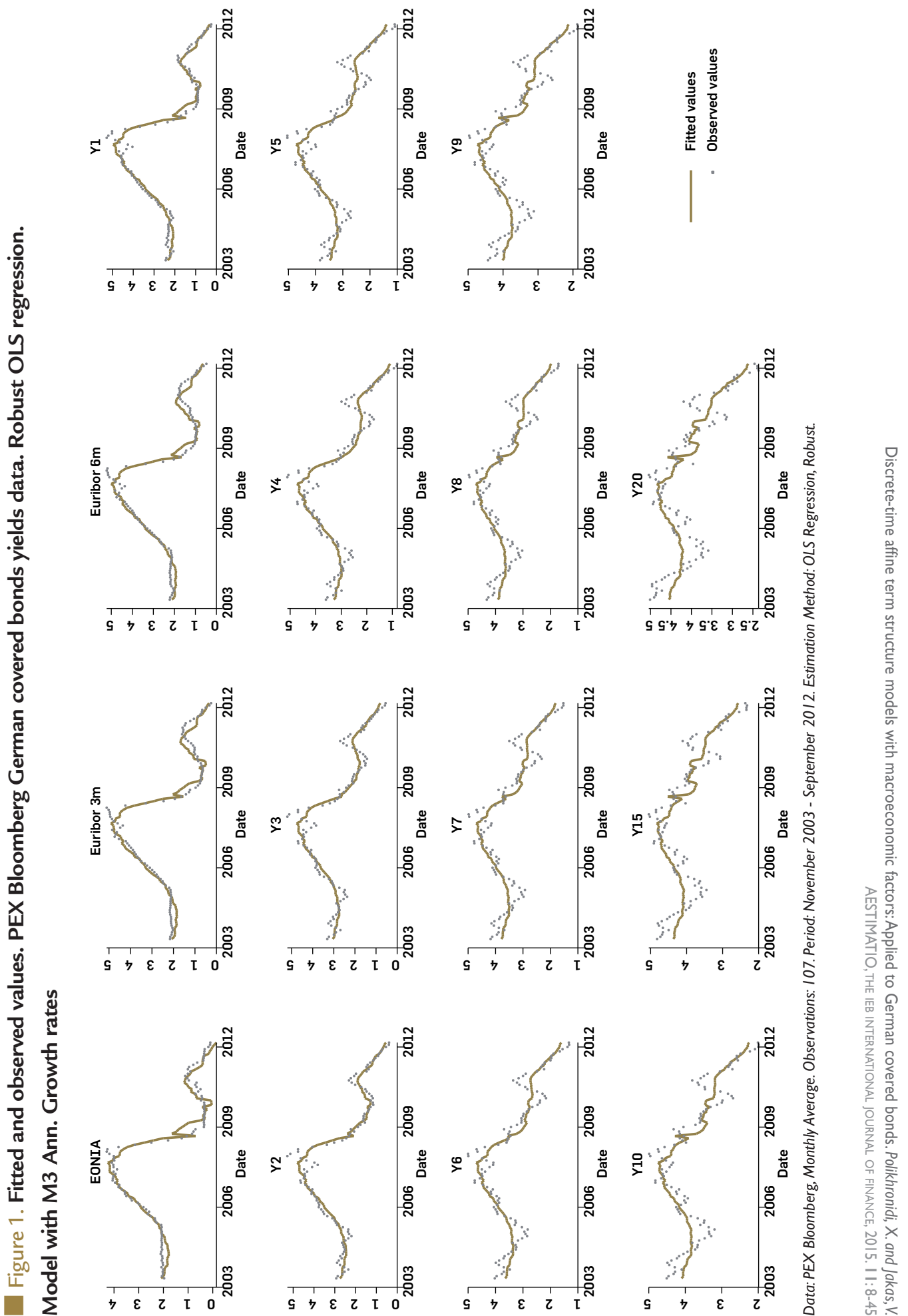


Figure 2. Coefficients on Macroeconomic variables and their statistical significance. PEX Bloomberg German covered bonds yields data. Robust OLS regression. Model with M3 Ann. Growth rates

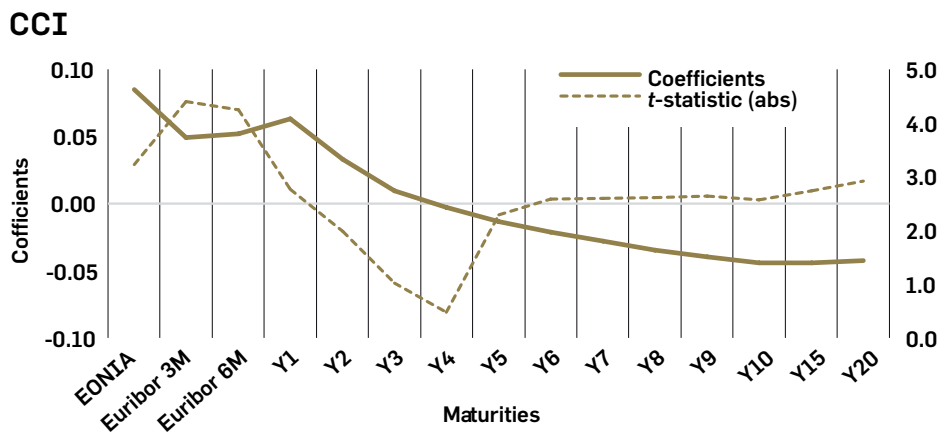

\section{Unemployment}

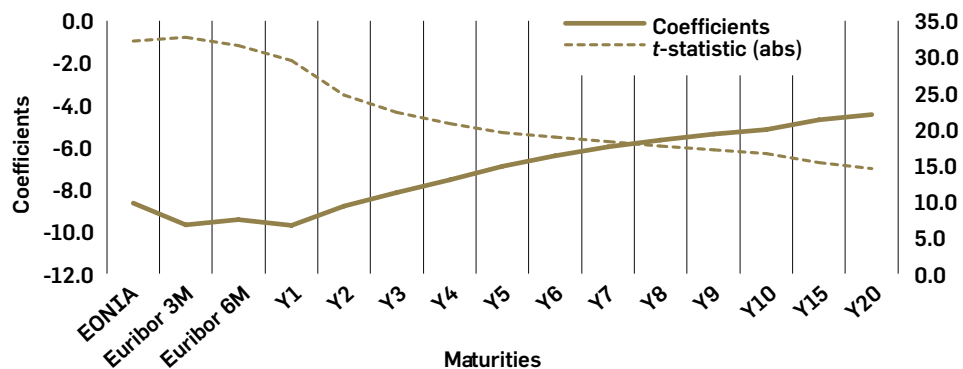

造

\section{M3 (annual growth rates)}

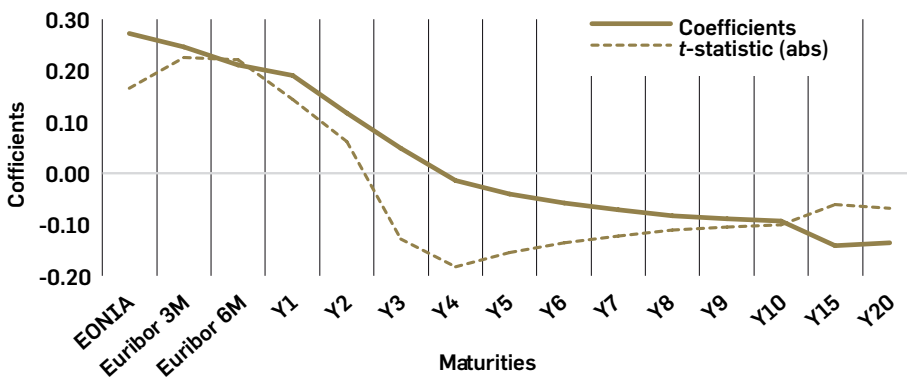

PPI

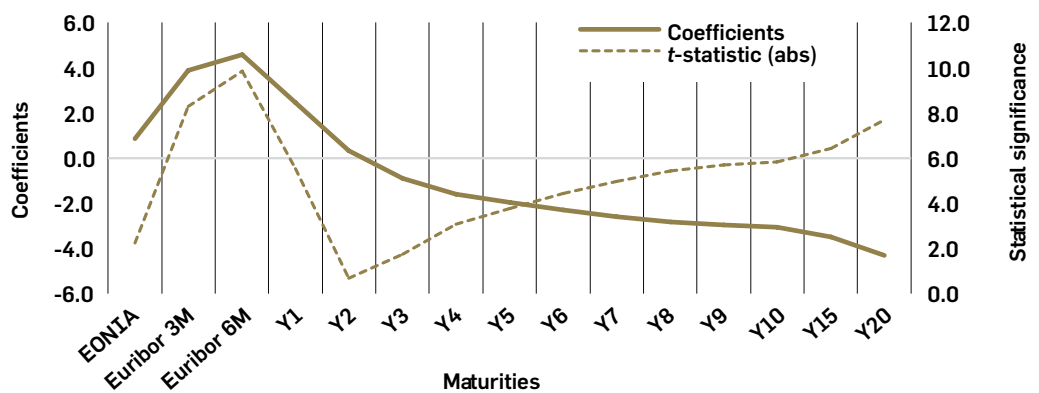

Data: PEX Bloomberg, Monthly Average. Observations: 107. Period: November 2003 - September 2012. Estimation Method: OLS Regression, Robust. 
We note that, as expected from the relationship defined by the model of Jakas (2011), $\mathrm{CCl}$ exhibits a positive relationship with short- and medium-term yields. Higher $\mathrm{CCl}$ values indicate improved economic consumer confidence for the near future, which in turn results in better expectations about future consumption growth. When expected consumption growth is high, the expected aggregate marginal utility growth decreases, and as a result, consumers lower the value of future cash flows, thus pushing prices of risk-free assets down and yields up. This works for German covered bonds, as they are negatively correlated with consumption growth. As with German sovereign bonds, covered bonds are risk-free assets and act as a "hedge" for times when consumption growth is low. This relationship is fully in line with a consumption-based asset pricing model.

Another potential explanation for the positive relationship between $\mathrm{CCl}$ and risk-free yields in the short- and medium-terms is the expectation that improved performance of the economy in the future might lead to higher interest rates. This expectation is in line with the implications of the Taylor policy rule, which suggests that the ECB reacts to the increased positive gap in real activity by increasing the level of the short rate. Thus, in anticipation of higher rates in the following time periods, the current demand on the markets for assets of certain maturities might fall, pushing their prices down and the yields up. However, $\mathrm{CCl}$ is negatively related to the yields of longer maturities and this relationship is also statistically significant. This finding for the longer maturities might result from the anticipated cyclical effects of consumption and saving. That is, as a result of the expected increase in interest rates in the short-and medium-terms, consumers expect the rate of savings to increase and the rate of expected consumption growth to decrease in the long run. Thus, the growth of marginal utility of consumption in the long run is expected to be higher, pushing the prices of risk-free assets of longer maturities up and the yields down. This observation is in line with the anticipated cyclical effect of the reaction policy of the ECB, where increased savings eventually lead to lower interest rates in the long-run and, therefore, to lower yields. Despite being economically meaningful and statistically significant, the magnitude of the effects of the $\mathrm{CCl}$ coefficients is, however, rather small.

Eurozone unemployment rates are also used in the estimation of the effect of real economic activity and of the expected consumption growth on the term structure of interest rates. As shown in Figure 2, all coefficients for the unemployment variable are negative, strikingly significant and - in absolute terms - decrease with maturity, both in terms of significance and the size of their economic impact. Thus, it seems that unemployment has a considerable influence on yield dynamics, particularly so on the shorter end of the curve. The negative coefficients for this macroeconomic variable are also fully in line with the theory, where the relationship between the interest rates and unemployment is expected to be negative. In particular, higher rates of unemployment lead to a 
decrease in the expected consumption growth and thus have a positive effect on the expected aggregate marginal utility. As a result, consumers place more value on future cash flows from the assets, the demand for the risk-free assets increases, as do prices, and yields fall. Another potential explanation for these findings is again provided by the Taylor policy rule: increased unemployment is likely to be a signal to households of an overall downturn in the macroeconomic environment and output. Market participants therefore expect the ECB to react to the negative gap in output by decreasing the short rate. Consequently, in anticipation of decreased interest rates and low inflation, households are willing to lock in the higher interest rates, thus driving demand for assets up and yields down. Consequently, these expectations on the market push the yield curve down, particularly at the lower end.

The effects of changes in the price level, holding other effects constant, are captured by the coefficients on PPI. They are all statistically significant, exhibit a substantial effect on interest rates movements and are entirely in line with the expectations implied by the theory. Jakas (2011) expects the changes to the price level to have a dual impact on the dynamics of interest rates, with the extent of these effects depending on the elasticity of substitution between the money and the capital markets. Figure 2 shows that the interest rates for the shorter maturities are positively related to PPI. The Taylor rule implies that an increased positive gap between the current and the target inflation would induce the ECB to increase the short rate. Therefore, the model reflects the well-known fact that the ECB responds to the changes in inflation by manipulating the short end of the yield curve. As expected, coefficients turn negative as maturity increases, and the statistical significance also increases in the longer end, representing the second effect, where consumers treat inflation as bad news for consumption growth. This becomes more pronounced at the longer end of the curve, where the elasticity of substitution between two markets is expected to be lower and an increase in inflation is expected to result in lower future consumption.

Figure 2, however, suggests that M3 index annual growth rates are not related to the yields in the pattern that is suggested by the model in Jakas (2011). The results of Jakas (2011) show that all coefficients are statistically significant except for the maturities of four and five years. In addition, and in contrast to our results, the coefficients exhibit a positive relation to the yields in the short- and medium-term maturities. Furthermore, they gradually vanish as maturity increases, subsequently becoming statistically significant negative values for the longer maturities. That is, if M3 growth increases, then yields are expected to grow at the front end but to decrease at the long end, albeit at a slower pace.

In fact, this particular finding is not entirely unexpected taking into consideration the two-pillar strategy of the ECB's monetary policy. The ECB adheres to the view that 
money growth has an impact on future inflation (Gerlach, 2004, p. 7). As part of its two-pillar strategy, the ECB performs not only economic analysis, but also closely traces the monetary developments for additional cross-checks of potential risks to price stability (ECB, 2009). An increased growth rate of the M3 index may signal to the ECB potential inflationary pressures in the medium term. Thus, to mitigate the excessive growth in the broad money aggregate and to constrain the inflationary pressures, the ECB increases the opportunity cost of holding liquid assets by adjusting the short end of the yield curve upwards. Similarly, a decrease in money growth might indicate subdued or deflationary price trends in the medium- or longer-terms. Thus, the ECB reacts to a decrease in the $\mathrm{M} 3$ growth by decreasing the short rate and so decreasing the opportunity cost of holding money-like assets. Gerdesmeier and Roffia (2003) also find that the interest rate decisions of the ECB are influenced by the money growth gap, which they define as the difference between the actual M3 growth rate and its benchmark value. The authors conclude that monetary dynamics plays a role as an additional significant element in a Taylor-like policy rule for the Eurozone. The finding by Gerdesmeier and Roffia (2003) also supports the statistically significant relation between the M3 index growth rate and yields in the short- and mediumterm. The negative relation for longer-term maturities can then be explained by the cyclicality effects of the ECB policy.

Other studies, however, argue that the overall monetary policy of the ECB is not considerably influenced by the dynamics of the monetary aggregates (Svensson, 2000; Gali, 2010). In fact, it is important to note that the ECB clearly emphasizes that it distinguishes policy-relevant movements in the $\mathrm{M} 3$ index growth rates from the deviations of a short-term "noisy" nature (ECB, 2007, p. 1). When making monetary policy decisions, the ECB performs more in-depth analysis than simply comparing the annual M3 growth rates to the benchmark of $4.5 \%$ (ECB, 2007, p. 1), and this may partially explain the overall low magnitude of the coefficients on the $\mathrm{M} 3$ index growth rate.

Figure 3 compares the dynamics of the $\mathrm{M} 3$ index growth rate with the movements in the ECB policy rate. The plot below demonstrates particularly large and persistent swings in the M3 growth in the period around the recent financial crisis. Figure 3 also shows that in the period from 2004 to the present time, the ECB policy rate and M3 growth rate have been characterized by some positive relationship. In contrast, the earlier period, from the inception of the euro up to 2003, is described by the negative/weak relationship between the two rates. In its Monthly Bulletin from July 2007, the ECB explains the different patterns in the movements of the two rates shown in Figure 3 with reference to the difference in the nature of the $\mathrm{M} 3$ growth dynamics as well as the relevance of these dynamics to price stability risk. The effect of the $M 3$ index growth rates on the inflation rate was considered by the ECB to be benign in the period prior to 2004 (ECB, 2007), although the accelerated M3 index growth in the period starting in 2004 
raised significant concerns in the ECB and motivated the decision of the Governing Council to begin to raise interest rate levels in December 2005 (ECB, 2007).

Figure 3. ECB Policy rate and M3 annual growth rate.

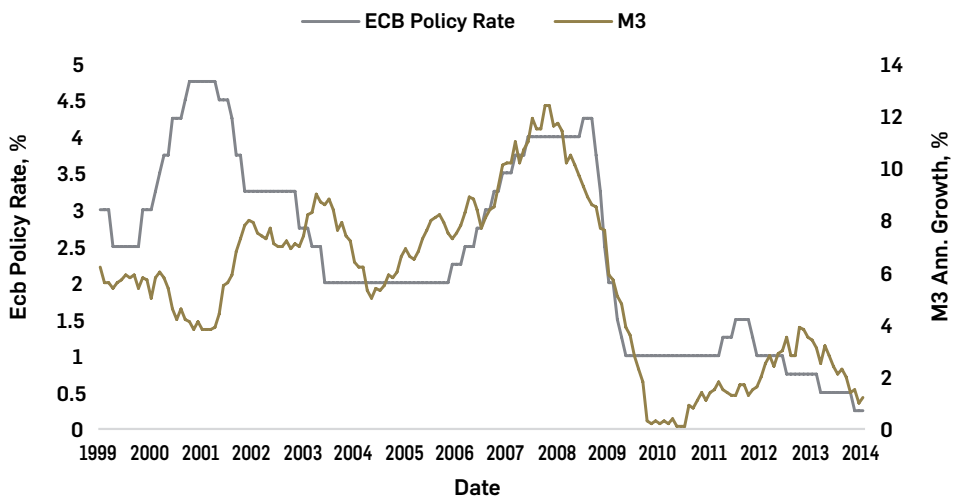

Data: ECB 2014

Overall, it seems that M3 index growth has a limited role in the monetary policy of $\mathrm{ECB}$, and so the coefficients on M3 index growth rate, seen in Figure 2, are of a low magnitude.

\section{Results obtained assuming no-arbitrage condition}

The results in this section are obtained using the discrete affine term structure models - Vasicek (1977) and CIR (1985) - mostly from Backus et al. (1998) and Duffie and Kan (1996), as described earlier. As in the previous section, the yields from the PEX Bloomberg data set are used for the empirical analysis. The models are calibrated using monthly macroeconomic data: (a) CCl; (b) unemployment rate; (c) M3 index annual growth rate; and (d) PPI. Each data set contains 107 observations for the period from November 2003 to September 2012. Both models - with coefficients described by equations (6) and (7) for the Vasicek model and by equations (11) and (12) for the CIR model, which are then entered into the equation (8) - are calibrated in MATLAB 8.3. The EONIA rate is taken as the benchmark rate and, therefore, its estimated coefficients on the four macroeconomic factors are used for the input in the models. The models are fitted by adjusting the risk parameter. For the Vasicek model, the results of calibration are summarized in Figure 4 and Figure 5. For the CIR model, the summary is provided in Figure 6 and Figure 7.

As Figure 4 suggests, the coefficients on the macroeconomic factors in the Vacisek model clearly reveal patterns largely similar to the OLS results, and so the economic interpretation is generally analogous to the analysis provided in the previous section. Yields exhibit a positive relationship to $\mathrm{CCl}$, PPI and M3, which diminish with maturity, 
gradually approaching zero. Contrary to what has been observed for the OLS results, for these three macroeconomic factors, the coefficients do not become negative for the yields of longer maturities. The coefficients on unemployment rate suggest a negative relationship with the covered bonds' yields. The results for the CIR model are graphically depicted in Figure 6 and, as expected, the coefficients obtained are almost identical to the Vasicek model coefficients. Both the CIR and the Vasicek coefficients tend to be more persistent than the OLS values and exhibit a smoother path across maturities. The CIR model captures the humped shape for PPI and M3 coefficients better than the Vasicek model and, therefore, appears to fit the observed values of average yield curve somewhat more accurately. However, both models appear overall to have a good fit to the observed yield curves. This can also be seen in Figure 5 and Figure 7, where the plots show that the two models reproduce the paths of the time series for the yields quite well, particularly for the maturities of the short- and medium-term.

\section{Figure 4. Coefficients on macroeconomic variables. Multifactor Vasicek model}
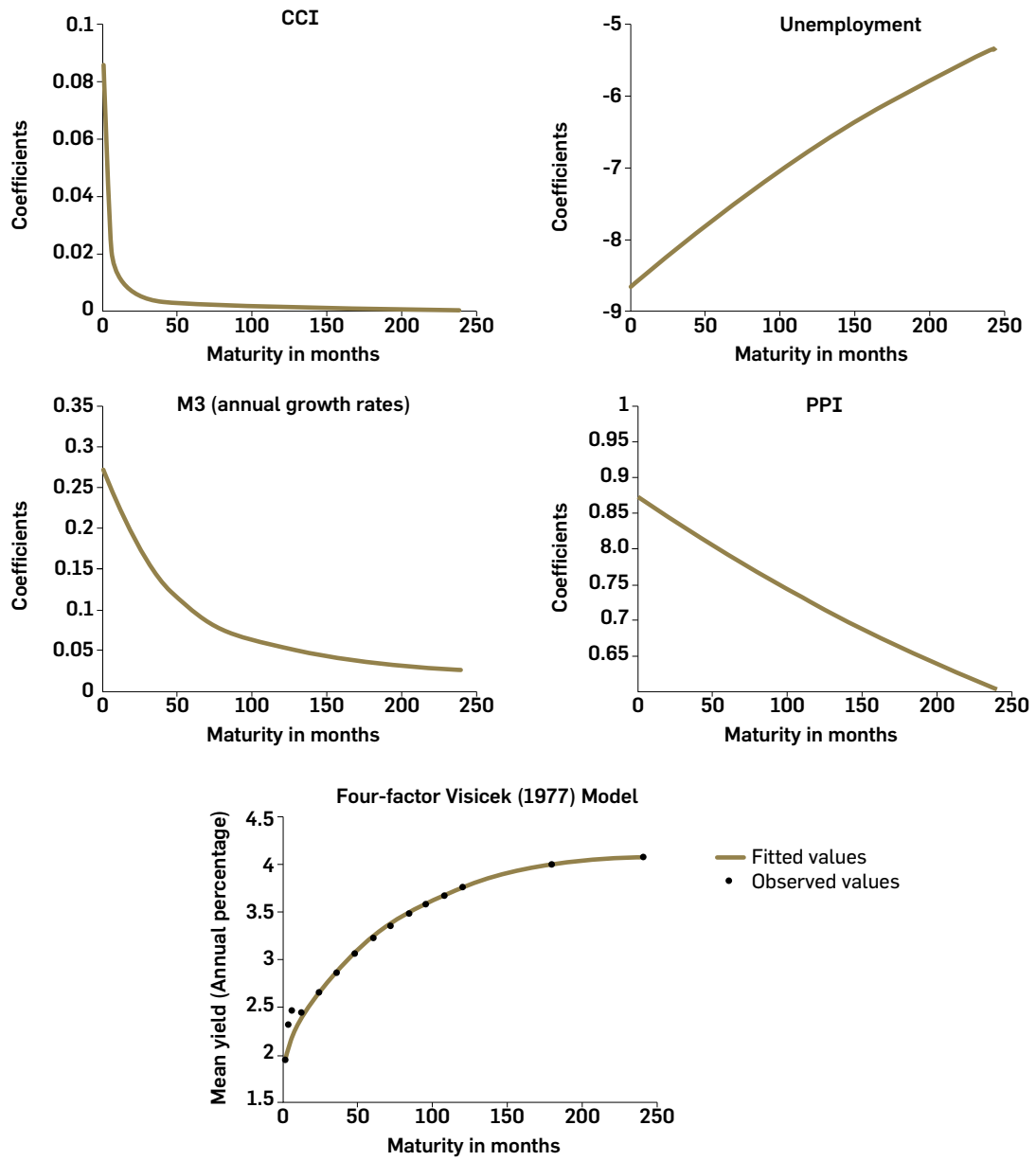

Data: PEX Bloomberg, Monthly Average. Period: November 2003 - September 2012. Model with M3 Ann. Growth Rates. 


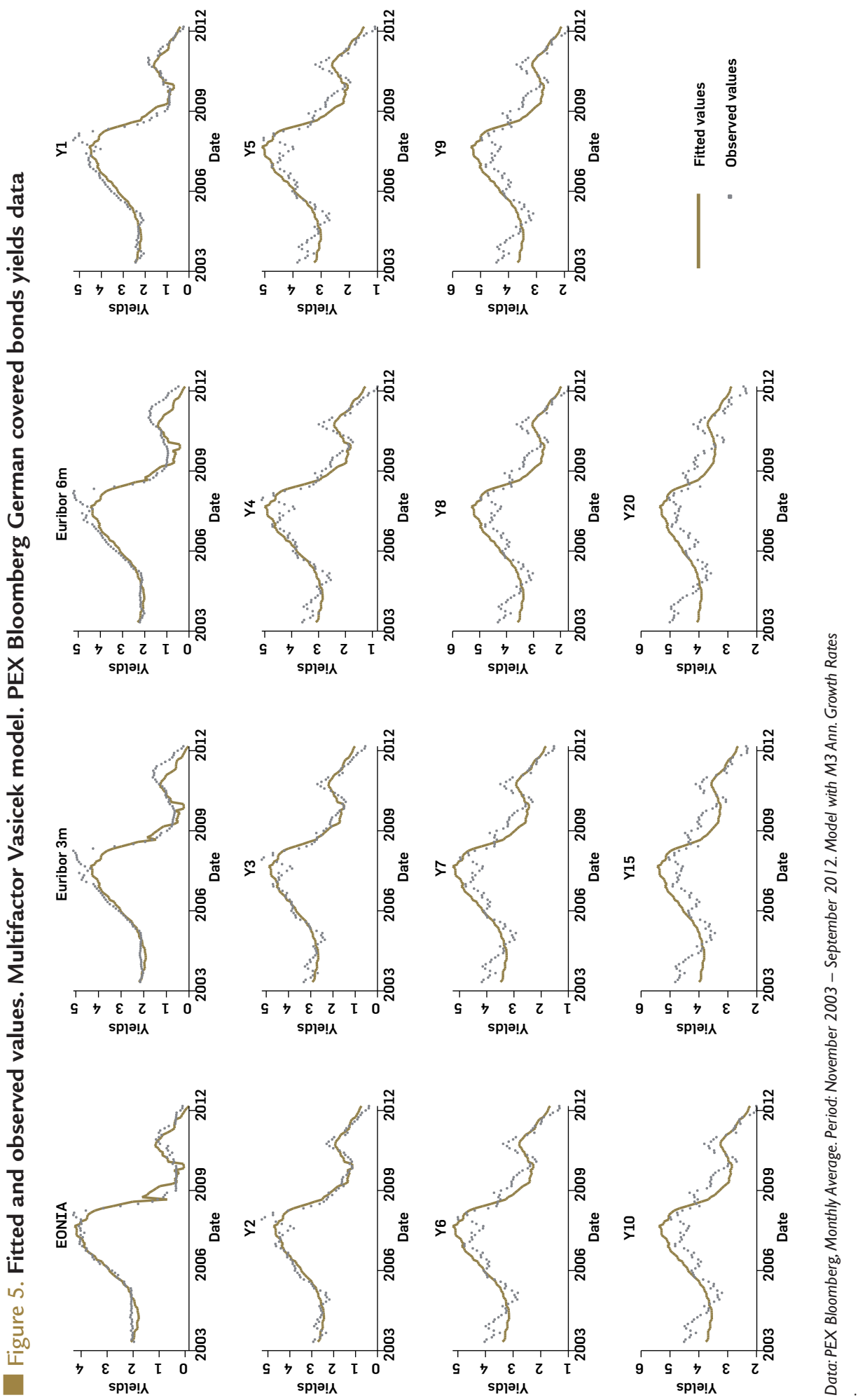


Figure 6. Coefficients on macroeconomic variables. Multifactor CIR model
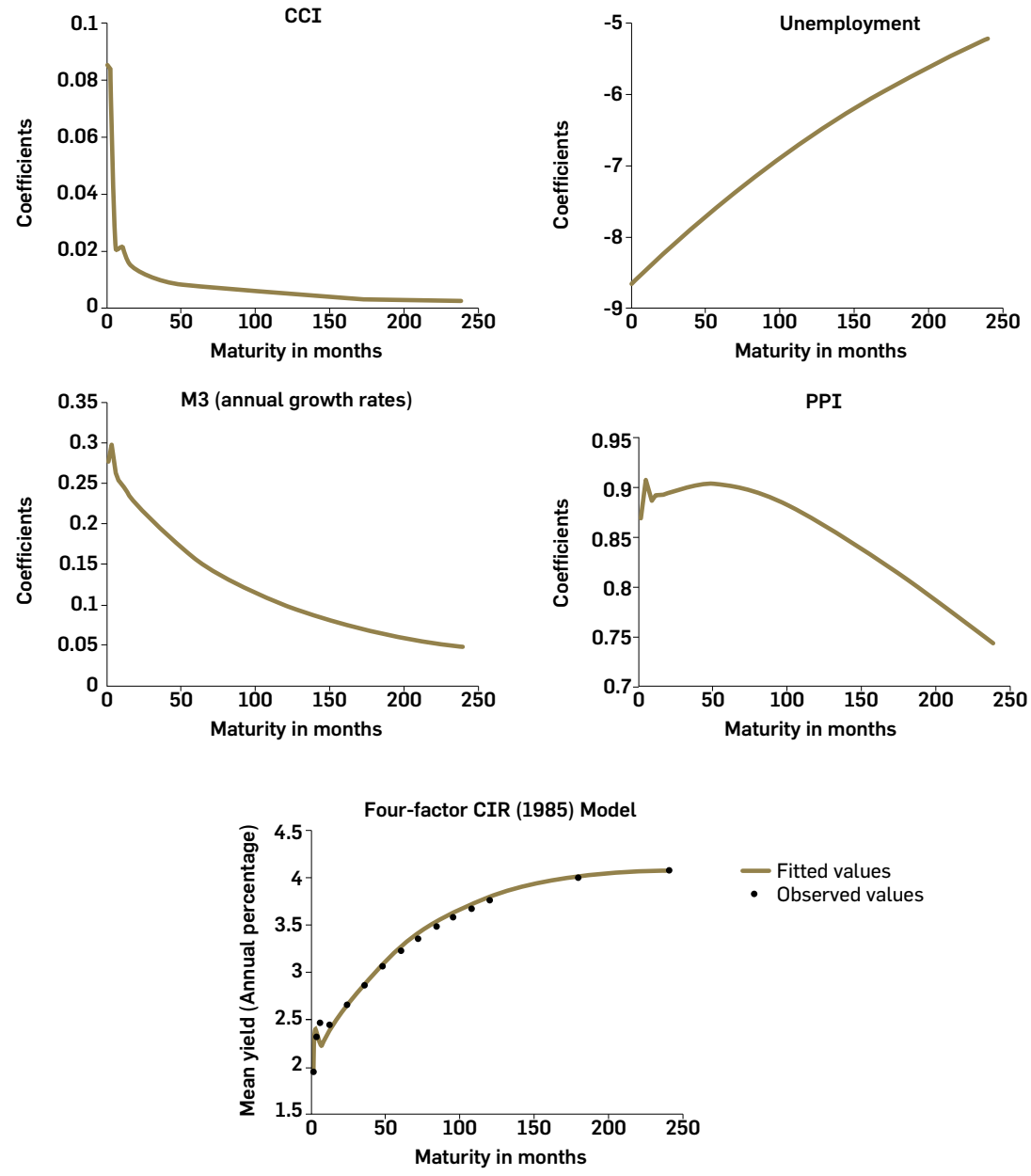

Data: PEX Bloomberg, Monthly Average. Observations: 107. Period: November 2003 - September 2012. Model with M3 Ann. Growth Rates. 


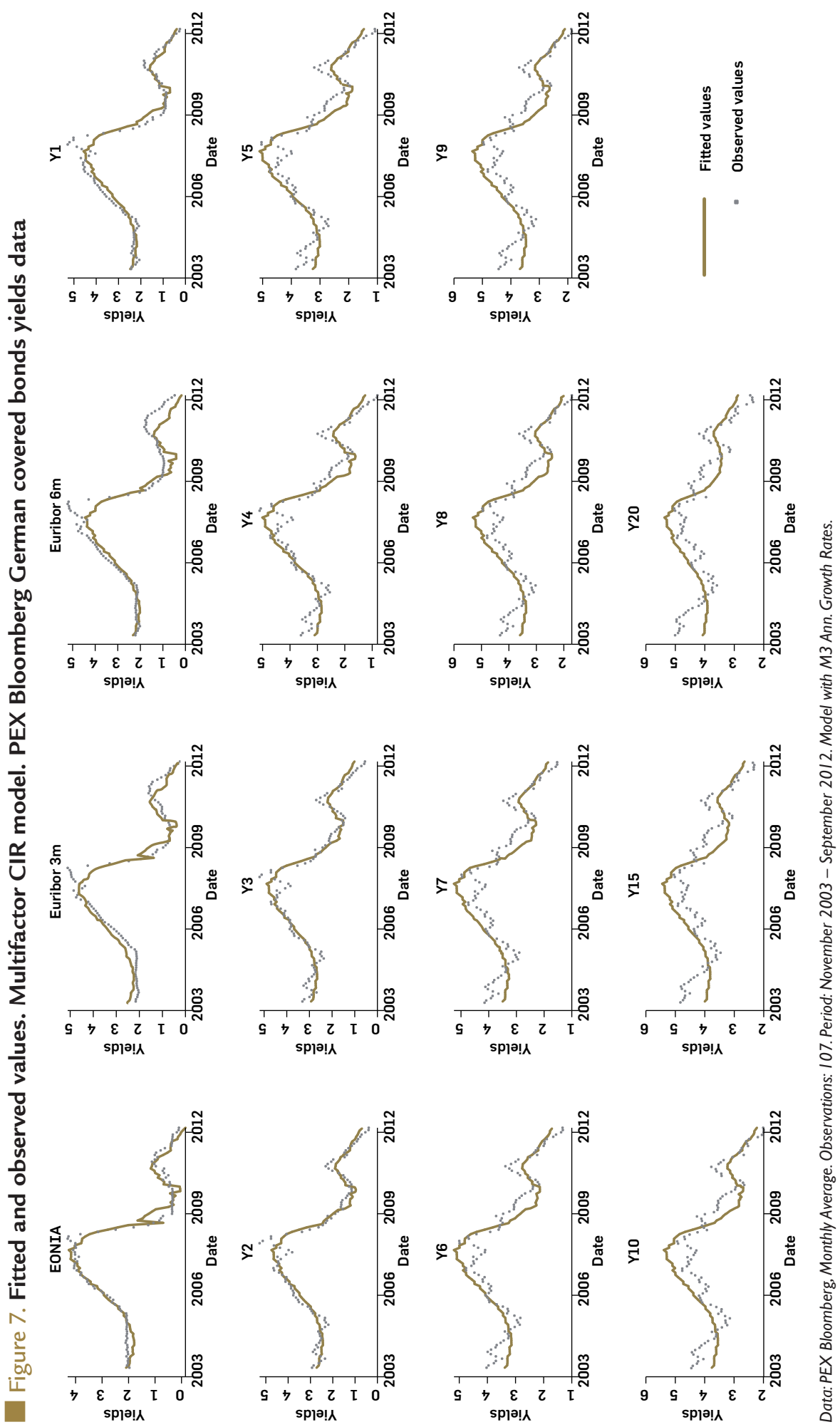




\section{Other results}

In general, the results of this study confirm the findings of Jakas $(2011,2012)$, where a similar analysis for the German government bonds was performed. These previous studies found that $\mathrm{CCl}$ and PPI exhibit a positive relationship for short- and medium-term maturities and with negative coefficients across all maturities for the unemployment rate. However, as explained above, the current study slightly modifies the approach by using M3 index growth rates instead of M3 outstanding amounts, and so the results for this macroeconomic factor differ from those in Jakas $(2011,2012)$. In contrast to the findings described above, the previous studies report a clearly negative relationship between the changes in M3 outstanding amounts and German government bond yields.

For the sake of comparison with the results in Jakas (2011, 2012), Figure 8 graphically summarizes the OLS coefficients for the model in equation (1) using M3 outstanding amounts or the so-called level. Figure 9 plots the absolute values for the respective tstatistics summarizing the statistical significance for the coefficients. There are three types of plots on the graphs - PEX Bloomberg, PEX VDP and PEX Bundesbank, and so the graphs now include not only the results for the PEX Bloomberg data, but also the estimations that were separately obtained using PEX VDP and PEX Bundesbank data series. All three data sets were run in Stata independently from each other and, as previously described in section III, the three data series differ by time periods, maturities available and number of observations. Therefore, the graphs do not appear to be entirely harmonious, however, they are jointly plotted on a common graph for a more convenient comparison and a general estimation of how stable the model is for different data sets. Further discussion on the performance of the model with respect to the different data sets is continued in subsequent paragraphs of this chapter.

Similar to Jakas $(2011,2012)$, when considering the outstanding amounts, Figure 8 confirms a negative pattern for the M3 coefficients for the short- and medium-term maturities of the yields in the PEX Bloomberg data. These coefficients are statistically significant and exhibit a stronger economic effect than coefficients obtained using M3 index growth rates. For the PEX Bloomberg data, the overall relationship pattern for PPI and unemployment remained the same, although the magnitude of these coefficients significantly changed. Furthermore, the coefficients for $\mathrm{CCl}$ are no longer significant, indicating a potential issue with the model or macroeconomic data used. While the models of Jakas $(2011,2012)$ generally fit the observed data, the differences implied by the introduction of changes into one of the four macroeconomic factors suggests that there may still be room for further improvement of the model.

To test for the stability of the model in the previous section, Figure 10 and Figure 11 compare the coefficients and their statistical significance for the yields from three dif- 
ferent data sets. As described above, for the graphs of this type, all three data sets are run in Stata separately and then plotted on a common graph. Initially the three data series differ by the time periods, maturities available, and number of observations. However, the coefficients, plotted on Figure 10 and Figure 11, were obtained for a fixed time period, where all the three data series overlap. Specifically, the sample period for the three sets is fixed at November 2003 - March 2012 resulting in 101 observations for each set. This approach allows us to eliminate the effects of the timeperiods that are specific to the data set and of the number of observations in the set. From Figure 10 we can clearly see that the results of the model are valid for all three data series. The minor variances observed in this figure arise most likely from the remaining differences in the length of maturities and measurement methods.

Figure 12 and Figure 13 compare the coefficients for the data sets using the entire time series available. These graphs clearly suggest that the findings, which were obtained using PEX Bloomberg, do not entirely hold with respect to the other two sets of time series. The differences in the behaviour of the coefficients across different data sets are most evident for the M3 and PPI macroeconomic factors. In particular, the M3 growth rates appear to have close-to-zero effect on the short-term maturities, which gradually increases in magnitude, with a negative sign. Thus, in contrast to PEX Bloomberg and PEX Bundesbank, an increase in the M3 index growth rates does not exert a positive effect on the yields of shorter maturities. For the coefficients on PPI, the difference is even more apparent. The PEX Bloomberg results suggest a positive relationship between $\mathrm{PPI}$ and the yields of shorter-maturities, while the findings from the two other data sets do not confirm this observation. Indeed, all coefficients are negative, and are mostly statistically significant. This difference in the results is most likely related to the sample period of each data set. Therefore, Figure 14 plots the coefficients for the PEX Bundesbank data series, limiting the observations to the precrisis period of January 2000 - June 2007. Comparing these results with the PEX Bundesbank coefficients for other periods that are shown in the Figure 10 and Figure 12 , the findings show that the sample period clearly plays an important role. For instance, the $\mathrm{CCl}$ coefficients in Figure 14 have increased in magnitude and exhibit a considerably more persistent behaviour than in Figure 10. Conversely, in line with the observation suggested by the ECB itself (see the section III), for the maturities starting from 1 Year, the M3 index growth rates exhibit either a rather weak or no relationship to the covered bonds yields. M3 coefficients are sizeable only for the very short-term rates both in terms of magnitude and statistical significance. PPI coefficients also conflict with results observed in Figure 10, where these now display a negative relationship with the yields of all maturities. The single exception that remained relatively robust to the change in the time period observed is the macroeconomic factor of unemployment rate, where the magnitude and statistical significance decreased but the overall pattern of the relationship with the yields did not change. 
Overall, the above results suggest that the models provide an economically meaningful explanation for the behaviour of the interest rates, although the results remain vulnerable to changes in the macroeconomic data and to the time periods observed. Therefore, there is potential for future research to improve this model.

Figure 8. Coefficients on macroeconomic variables. All time series for three data sets. Robust OLS regression. Model with M3 outstanding amounts

\section{CCI}

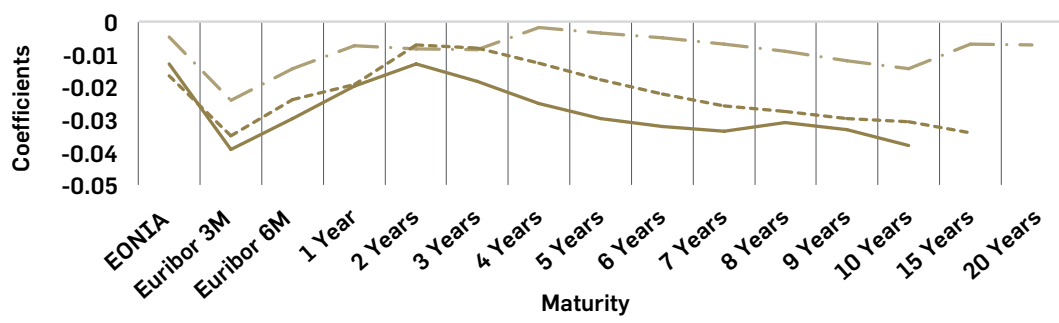

\section{Unemployment}

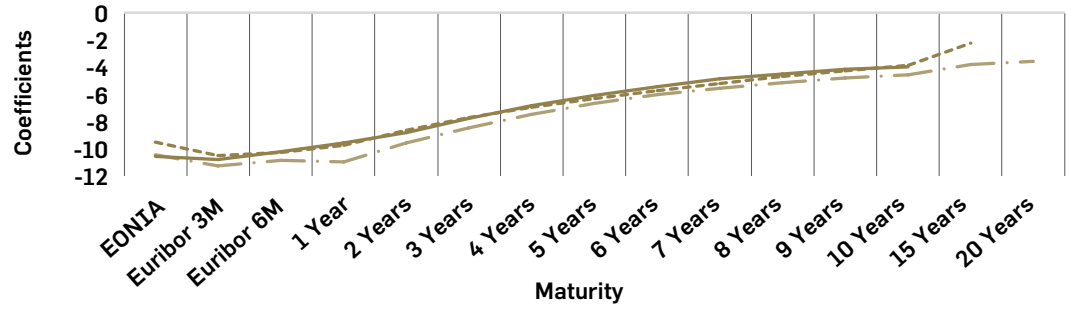

\section{M3 (outstanding amounts)}

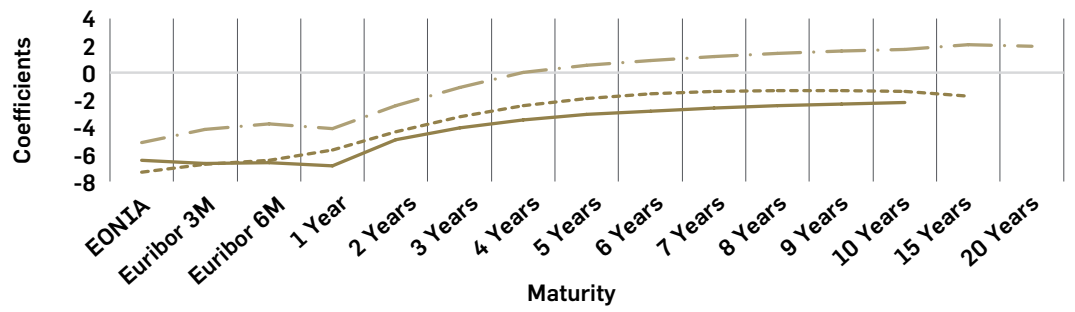

PPI

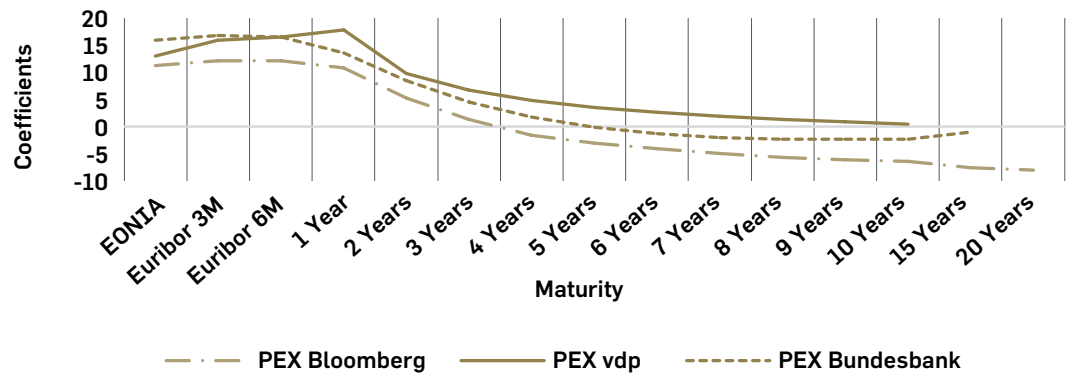

Data: PEX Bloomberg, PEX vdp and PEX Bundesbank, Monthly Average. Observations: varying across data sets. Periods: varying across data sets. Estimation Method: OLS Regression, Robust. 
Figure 9. Statistical significance of coefficients on macroeconomic variables. All time series for three data sets. Robust OLS regression. Model with M3 outstanding amounts

\section{CCI}

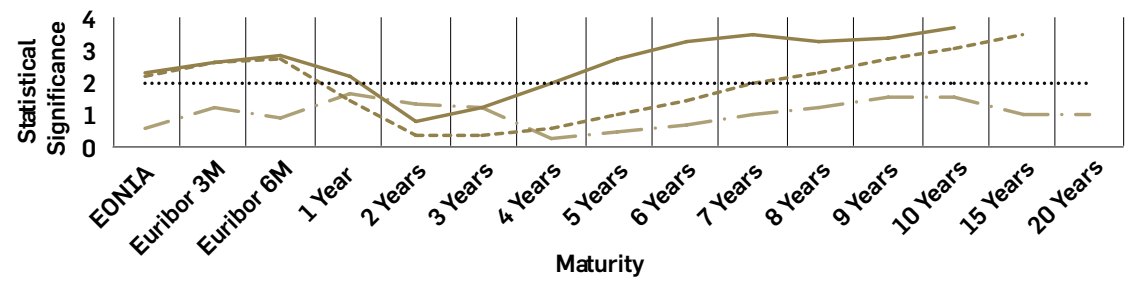

\section{Unemployment}

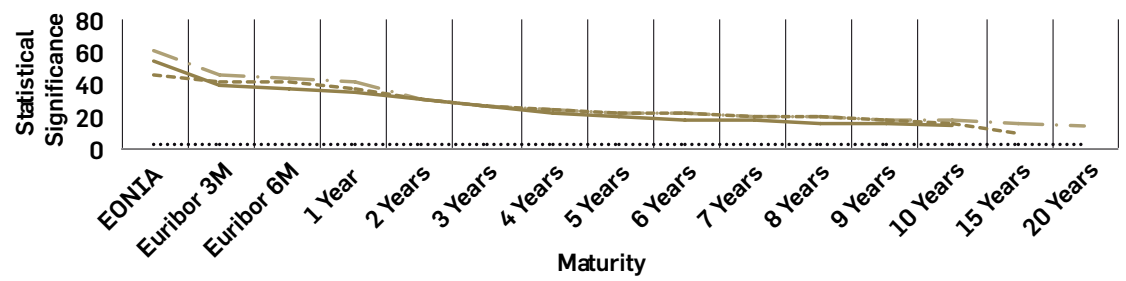

\section{M3 (outstanding amounts)}

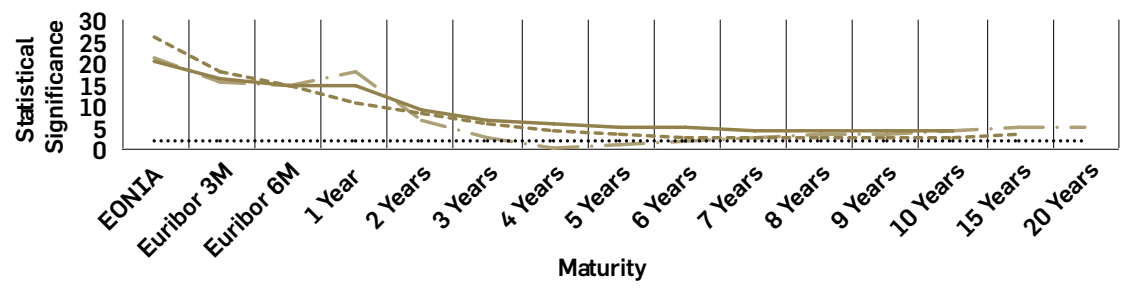

\section{PPI}

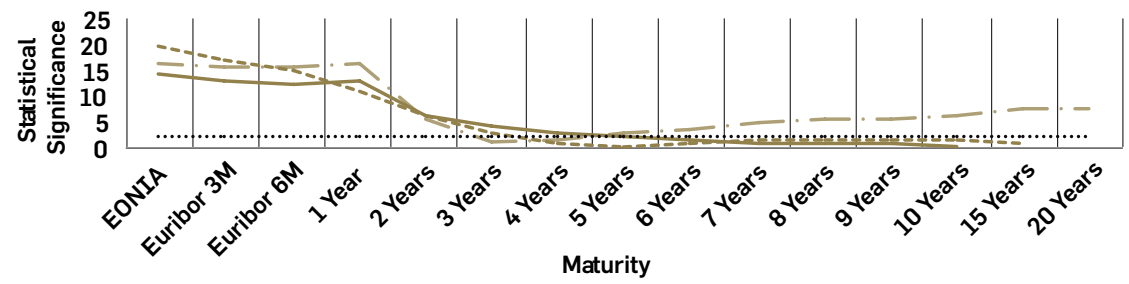

- - PEX Bloomberg

PEX vdp

PEX Bundesbank

$5 \%$ significance level

Data: PEX Bloomberg, PEX vdp and PEX Bundesbank, Monthly Average. Observations: varying across data sets. Periods: varying across data sets. Estimation Method OLS Regression, Robust. Statistical significance: absolute values of $t$-statistics. 
Figure 10. Coefficients on macroeconomic variables. Matched time series for three data sets. Robust OLS regression. Model with M3 Ann. Growth rates

\section{CCI}

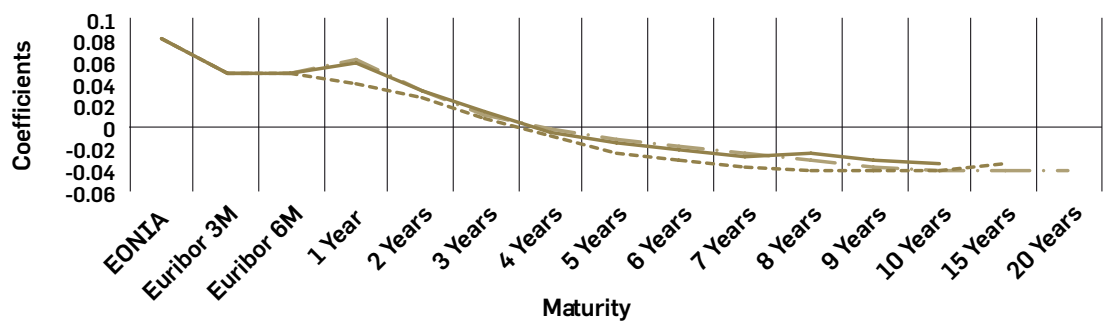

\section{Unemployment}

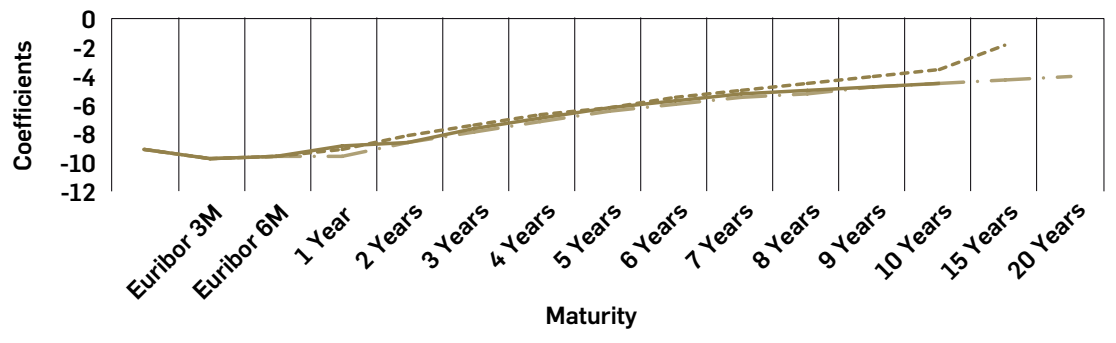

M3 (annual growth rates)

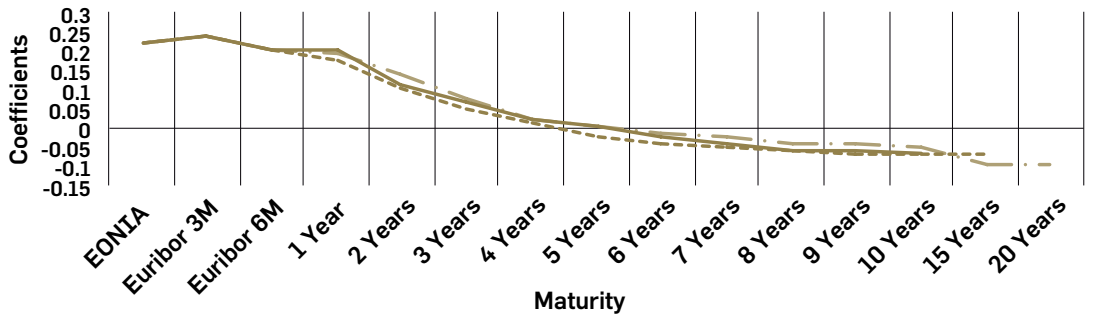

\section{PPI}

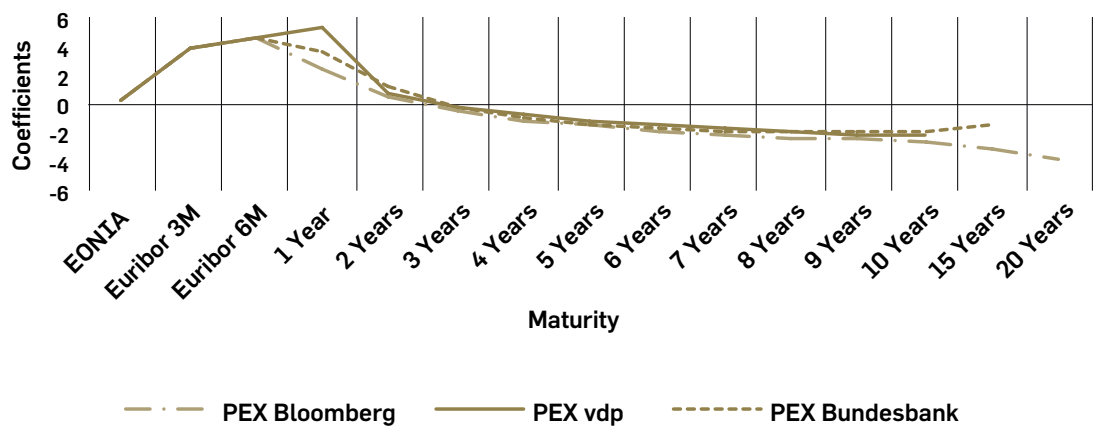

Data: PEX Bloomberg, PEX vdp and PEX Bundesbank compared, Monthly Average. Observations: I0I. Period: November 2003 March 2012. Estimation Method: OLS Regression, Robust. 
Figure 11. Statistical significances of coefficients on macroeconomic variables. Matched time series for three data sets. Robust OLS regression. Model with M3 Ann. Growth rates

\section{CCI}

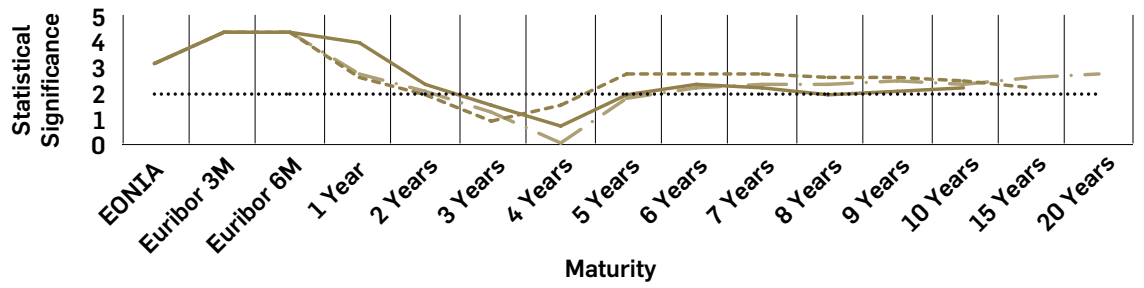

\section{Unemployment}

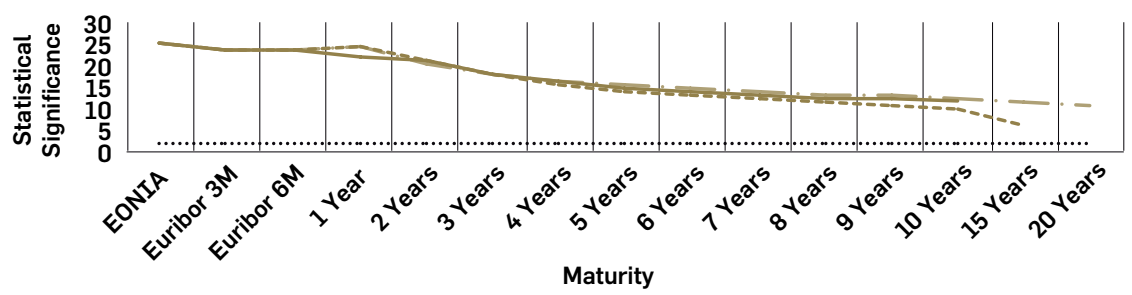

\section{M3 (annual growth rates)}

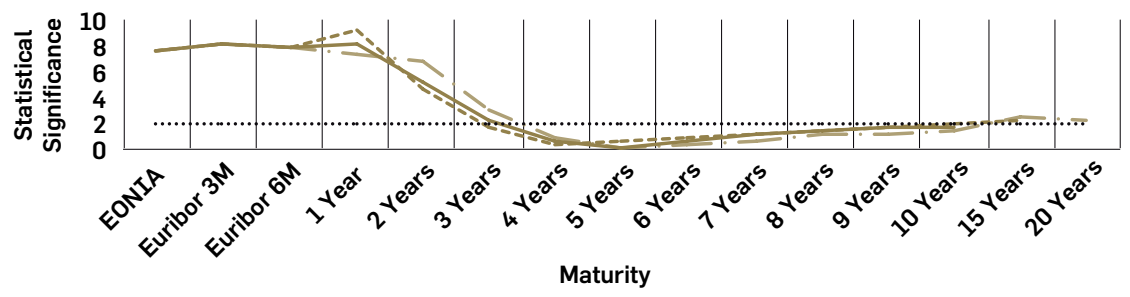

\section{PPI}

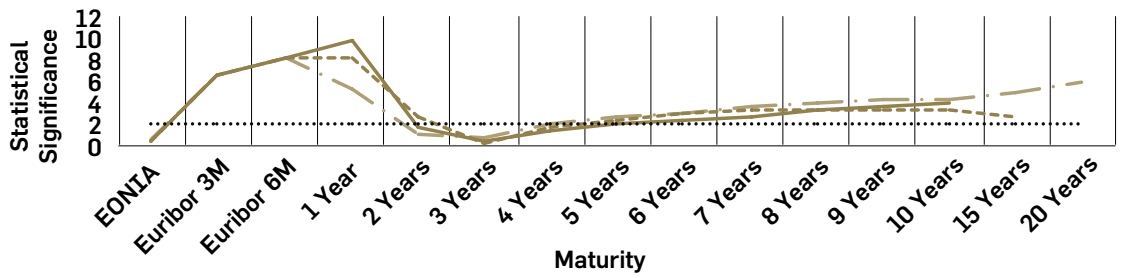


Figure 12. Coefficients on macroeconomic variables. All time series for three data sets. Robust OLS regression. Model with M3 Ann. Growth rates

CCI

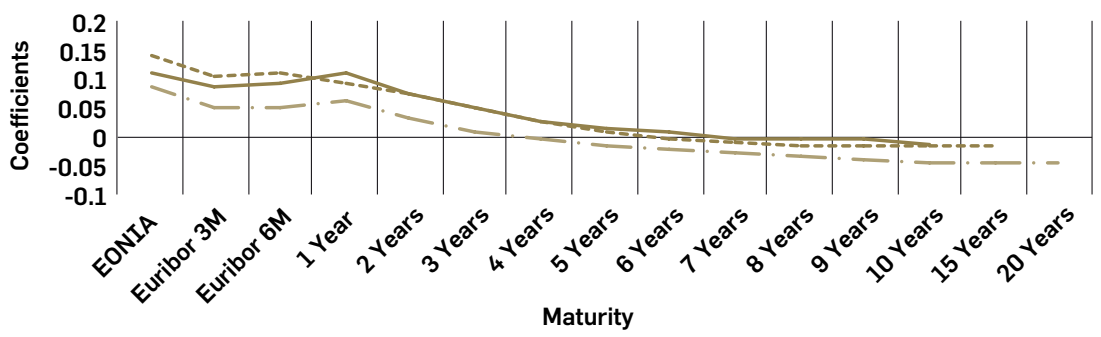

\section{Unemployment}

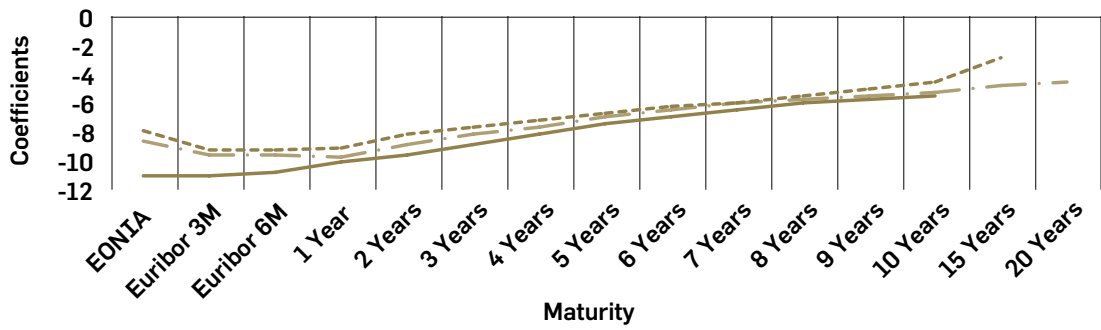

\section{M3 (annual growth rates)}

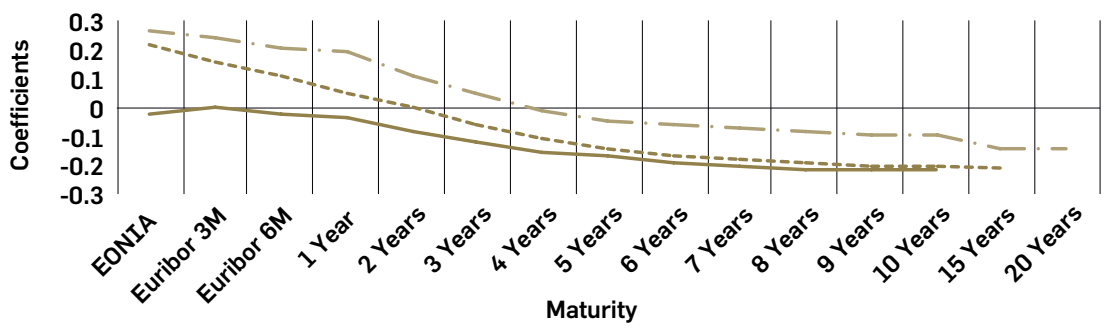

PPI

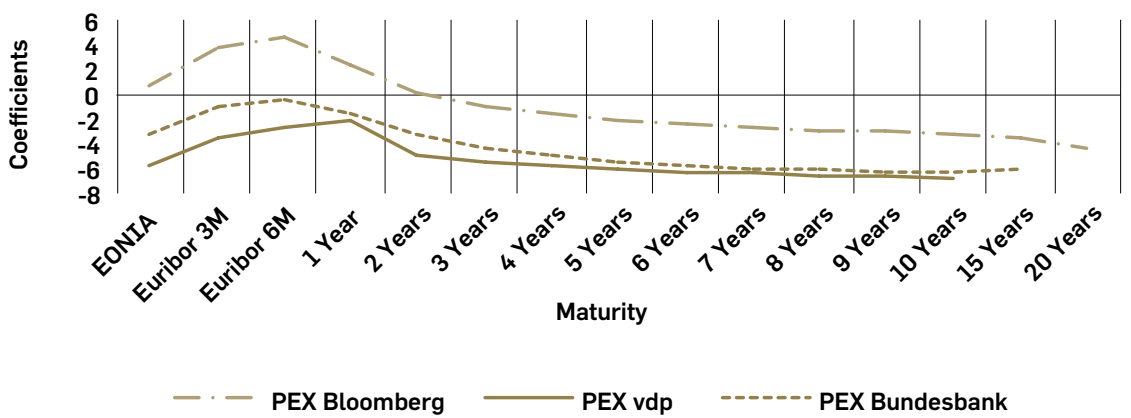

Data: PEX Bloomberg, PEX vdp and PEX Bundesbank compared, Monthly Average. Observations: varying across data sets. Period: varying across data sets. Estimation Method: OLS Regression, Robust. 
Figure 13. Statistical significances of coefficients on macroeconomic variables. All time series for three data sets. Robust OLS Regression. Model with M3 Ann. Growth rates

CCI

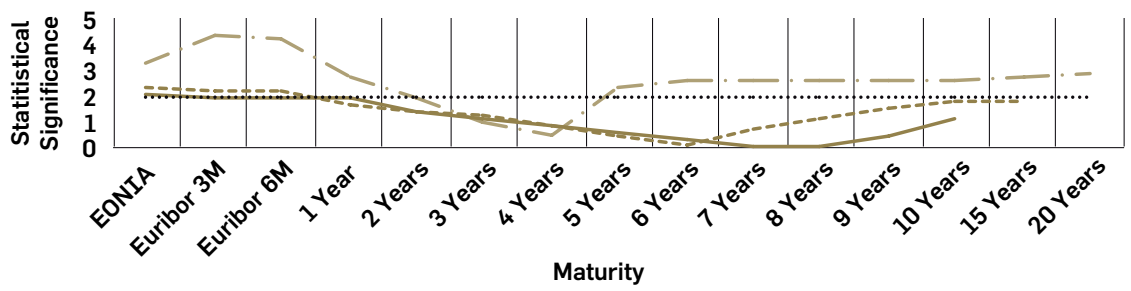

\section{Unemployment}

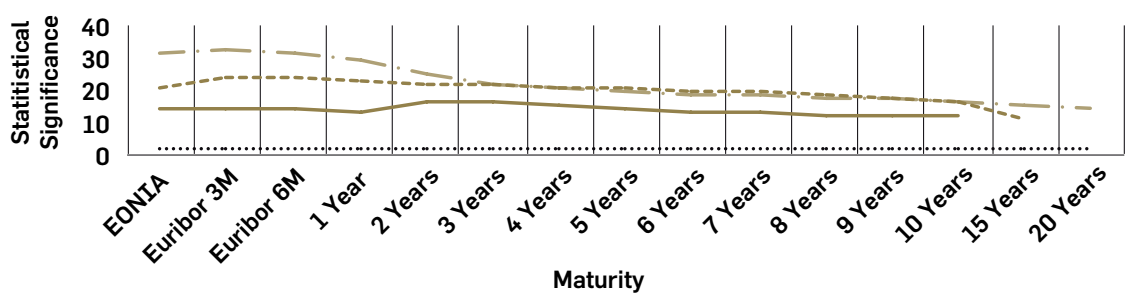

\section{M3 (annual growth rates)}

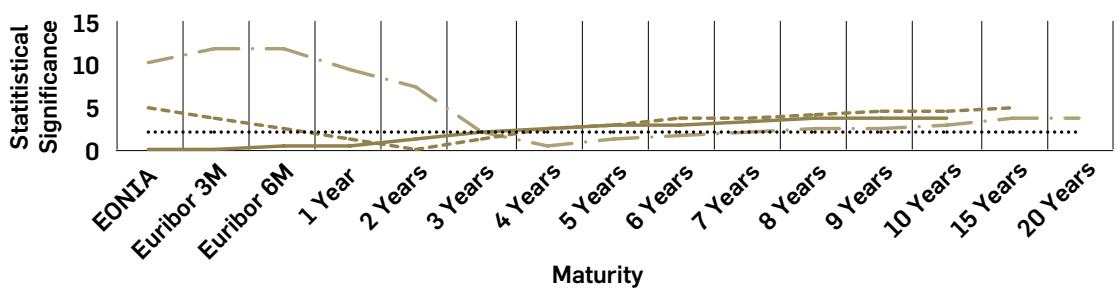

PPI

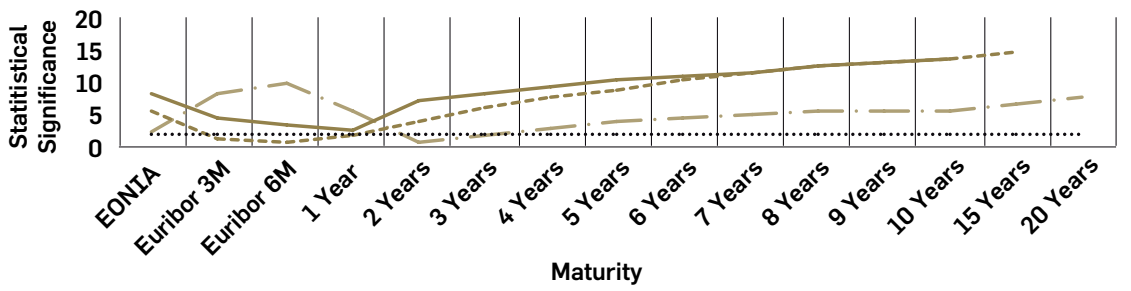

—- PEX Bloomberg — PEX vdp ----- PEX Bundesbank ……...5\% significance level 
Figure 14. Coefficients on macroeconomic variables and their statistical significance. Pre-crisis time series for pex Bundesbank German covered bonds yields data. Robust OLS regression. Model with M3 Ann. Growth rates

\section{CCI}

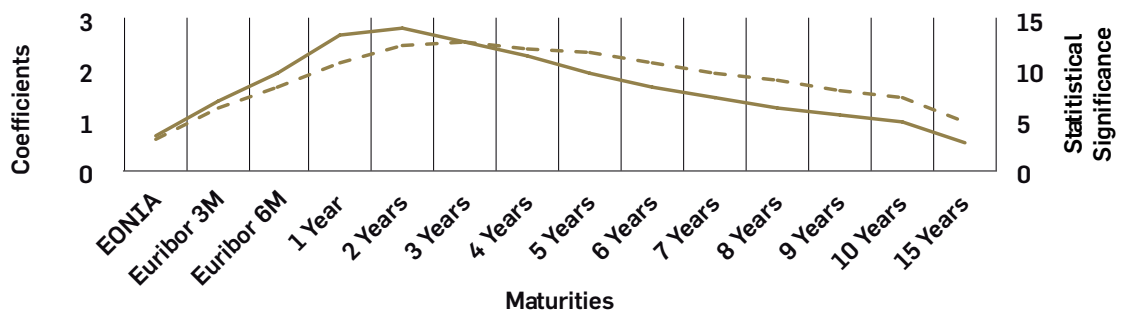

Unemployment

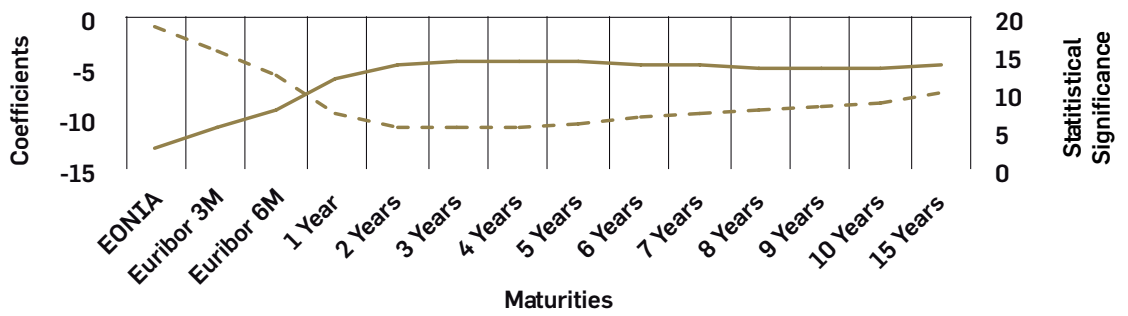

\section{M3 (annual growth rates)}

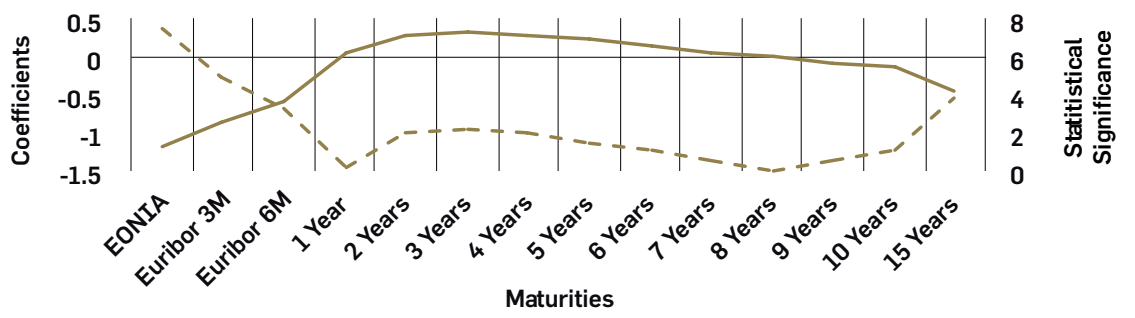

\section{PPI}
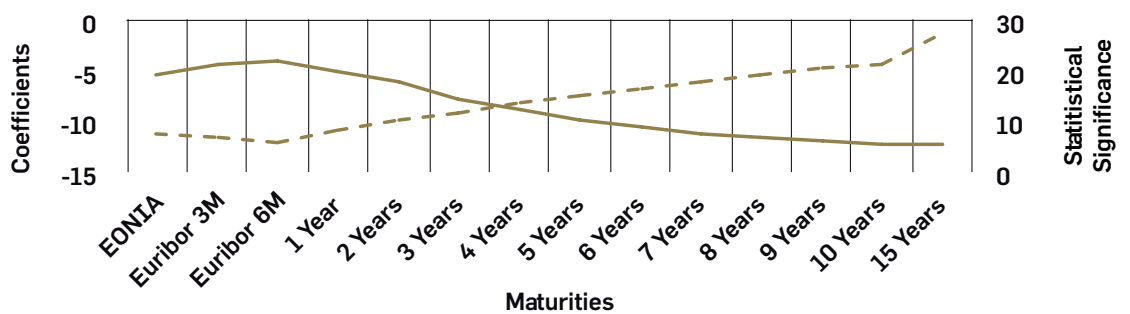

Maturities 


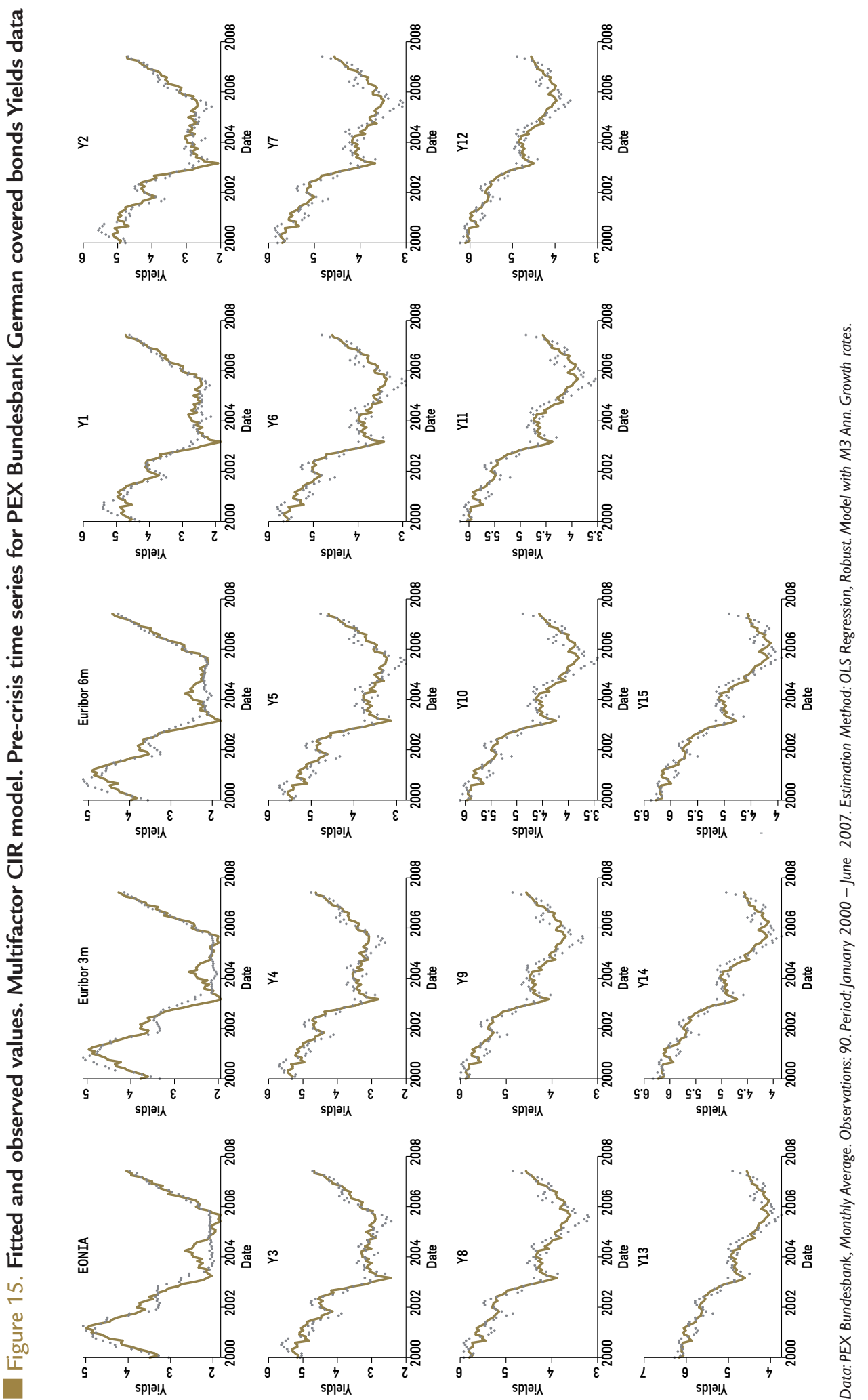




\section{Conclusions and final remarks}

The purpose of this study is to apply the term structure of the interest rates model to German covered bond yields and from this explain its dynamics using macroeconomic factors in a similar set up to Jakas $(2011,2012)$. This study employs both approaches to the affine models: 1) including and, 2) disregarding the so-called no-arbitrage condition. Our findings in this paper provide macroeconomic interpretations of the movements of German covered bond yields, in line with current economic theories and general observations in the available literature. Results produced by the models in this study fit the observed values remarkably well; particularly so for the yields at the lower end of the curve. Overall, calculations in this paper confirm the observations in the macrofinance literature suggesting that macroeconomic factors have a strong explanatory power in the movements of the term structure of interest rates. Similar to previously published results, we found that the influence of macroeconomic variables is more pronounced at the lower end of the yield curve.

Despite the good performance of the models described above, there is still potential for further improvement. First, additional research on the choice of macroeconomic factors included in the models as well as on their respective macroeconomic data may be useful. In this study, the M3 outstanding amounts have been replaced by the M3 index growth rates since the latter are expected to capture the dynamics of the ECB monetary policy more accurately. However, we observed that the M3 factor has a rather weak explanatory power, since the pattern of its relation to the yields of covered bonds significantly depends on the time period considered. The potential reasons for this inconsistency of $\mathrm{M} 3$ coefficients with time are most likely rooted in the nature of this indicator, as discussed in the respective sections of this paper. Furthermore, the $\mathrm{CCl}$ data also tends to have coefficients of smaller magnitude and weaker stability across sample periods, which may be explained either by the survey-nature of this indicator or by other potential weaknesses of the model.

Second, the results of the models may be affected by the stationarity of the yields data. The time series of German covered bond yields appear to show an overall decreasing trend, while at the same time the Dickey-Fuller test (not reported here) fails to reject the unit root. The results of the robust OLS regression on the first differences (not reported) also appear to be rather weak. The trends in the prices of covered bonds might be influenced by the changes in the issuing and the outstanding amounts of the German Pfandbriefs, which have been significantly reduced over the last 10 years. This decrease in supply of the German covered bonds might be aggravated by the increased demand for safer investments such as German Pfandbriefs during the post-crisis period. The reduction in the total amounts has been driven by the German public covered bonds and we therefore intend to perform a separate analysis of mortgage Pfandbriefs in the near future. 
Altimari, S.N. (2001). Does money lead inflation in euro area? ECB Working Paper 63. Retrieved from https://www.ecb.europa.eu/pub/pdf/scpwps/ecbwp063.pdf. $\square$

Ang, A. and Piazzesi, M. (2003). A no-arbitrage vector autoregression of term structure dynamics with macroeconomic and latent variables, Journal of Monetary Economics, 50(4), pp. 745-787.

Ang, A., Dong, S. and Piazzesi, M. (2004). No-arbitrage Taylor rules. NBER Working Paper 13448. Retrieved from http://www.nber.org/papers/w13448.

Audley, D., Chin, R. and Ramamurthy, S. (2002). Term structure modeling. In F. J. Fabozzi (Ed.), Interest rate, term structure and valuation modeling, John Wiley \& Sons Inc., pp. 93-136.

Backus, D.K., Foresi, S. and Zin, S.E. (1994). Arbitrage opportunities in arbitrage-free models of bond pricing. NBER Working Paper 5638. Retrieved from http://www.nber.org/papers/w5638/.

Backus, D.K., Foresi, S. and Telmer, C. (1998). Discrete time models of bond pricing. NBER Working Paper 6736. Retrieved from http://www.nber.org/papers/w6736.

Becker, D. (1991). Stylized historical facts regarding Treasury interest rates from 1955 to 1994, Technical report, Lincoln National, Fort Wayne, Indiana.

Bliss, R.R. (1997). Movements in the term structure of interest rates, Economic Review, 4, pp. 16-33.

Breeden, D.T. (1979). An intertemporal asset-pricing model with stochastic consumption and investment opportunities, Journal of Financial Economics, 7(1), pp. 265-296.

Breeden, D.T. and Litzenberger, R.H. (1978). Prices of state-contingent claims implicit in option prices, Journal of Business, 51(4), pp. 621-651.

Campbell, J.Y. (1986). A defense of traditional hypothesis about the term structure of interest rates, Journal of Finance, 41(1), pp. 183-193.

Campbell, J.Y. and Shiller, R.J. (1991). Yield spreads and interest rates movements: A bird's eye view, Review of Economic Studies, 58(3), pp. 495-514.

Chan, K.C., Karolyi, A.G., Longstaff, F.A. and Sanders, A.B. (1992). An empirical comparison of alternative models of the short-term interest rates, Journal of Finance, 47(3), pp. 1209-1227.

Cheyette, O. (2002). Interest rate models. In F. J. Fabozzi (Ed.), Interest rate, term structure and valuation modeling, pp. 3-25, John Wiley \& Sons, Hoboken, NJ.

Choudhry, M. (2002). An introductory guide to analyzing and interpreting the yield curve. In F. J. Fabozzi (Ed.), Interest rate, term structure and valuation modeling, pp. 73-91, John Wiley \& Sons, Hoboken, NJ.

Clarida, R.H., Sarno, L., Taylor, M.P. and Valente, G. (2006). The role of asymmetries and regime shifts in term structure of interest rates, Journal of Business, 79(3), pp. 1193-1225.

Cochrane, J.H. (2001). Asset pricing, Princeton, NJ: Princeton University Press.

Cox, J.C., Ingersoll, J.E. and Ross, S.A. (1981). A re-examination of traditional hypotheses about the term structure of interest rates, Journal of Finance, 36(4), pp. 769-799. 
Cox, J.C., Ingersoll, J.E. and Ross, S.A. (1985). A theory of the term structure of interest rates, Econometrica, 53(2), pp. 385-407.

Culbertson, J.M. (1957). The term structure of interest rates, The Quarterly Journal of Economics, 71(4), pp. 485-517.

Dai, Q. and Singleton, K.J. (2000). Specification analysis of affine term structure models, Journal of Finance, 55(5), pp. 1943-1978.

Dombert, A. (2014). The euro area, the German economy and the Pfandbiref. Speech at the Pfandbrief seminar in Tokyo February 18, 2014, Deutsche Bundesbank, Frankfurt am Main. Retrieved from http://www.bundesbank.de/ Redaktion/EN/Reden/2014/2014_02_18_dombret.html. ש

Duffie, D. (2001). Dynamic asset pricing theory (3rd ed.), Princeton University Press, Princeton, NJ.

Duffie, D. and Kan, R. (1996). A yield-factor model of interest rates, Mathematical Finance, 6(4), pp. 379-406.

Economic Commission for Europe (2014). In-depth review of leading, composite and sentiment indicators. Geneva: Bureau of the Conference of European Statisticians. Retrieved from http://www.unece.org/fileadmin/DAM/stats/ documents/ece/ces/2014/ECE_CES_2014_10-In-depth_review_of_leading_composite_and_sentiment.pdf. $\square$

European Central Bank (1998a). A stability oriented monetary-policy strategy for the ESCB. ECB Press Release October 13, 1998. Frankfurt am Main: ECB. Retrieved from https://www.ecb.europa.eu/press/pr/date/1998/ html/pr981013__.en.html. $\square$

European Central Bank (1998b). The quantitative reference valuefor monetary growth. ECB Press Release December 1, 1998. Frankfurt am Main: ECB. Retrieved from http://www.ecb.europa.eu/press/pr/date/1998/ html/pr981201_3.en.html.

European Central Bank (2007). Interpreting Monetary Developments since 2004. ECB Monthly Bulletin, July, 5174. Retrieved from https://www.ecb.europa.eu/pub/pdf/other/pp51-74_mb200707en.pdf?47c2999769055bb 71ad6f9023d86fe4f.

European Central Bank (2008). Covered Bonds in the EU Financial System. Retrieved from http://www.ecb. europa.eu/pub/pdf/other/coverbondsintheeufinancialsystem200812en_en.pdf.

European Central Bank (2009). Monetary Analysis in an Environment of Financial Turmoil, ECB Monthly Bulletin, November, 81-96. https://www.ecb.europa.eu/pub/pdf/other/art2_mb200911en_pp81-96en.pdf. $\square$

European Central Bank (2011). The monetary policy of the ECB ( $3^{\text {rd }}$ ed), European Central Bank, Frankfurt am Main. .Retrieved from http://www.ecb.europa.eu/pub/pdf/other/monetarypolicy201len.pdf. $\square$

European Central Bank (2014). BSI Series and dataset level information: Explanation page, ECB Statistical Data Warehouse, ECB DG Statistics, Frankfurt am Main. Retrieved from http://sdw.ecb.europa.eu/browse Explanation. do?node=qview\&SERIES_KEY=117.BSI.M.U2.Y.V.M30.X.I.U2.2300.Z01.A. $\square$

European Commission (2014). Key indicators for the euro area. Retrieved from http://ec.europa.eu/economy finance/db_indicators/key_indicators/index_en.htm. $\square$

ECBC - European Covered Bond Council (2013). European Covered Bond Fact Book. ECBC Publication. Retrieved from: http://ecbc.hypo.org/Content/Default.asp?PageID=501.

Eurostat (2012). Handbook of industrial producer price indices (PPI), Eurostat Methodologies and Working Papers. Publications Office of European Union, Luxemburg. Retrieved from http://epp.eurostat.ec.europa.eu/cache/ ITY_OFFPUB/KS-RA-12-020/EN/KS-RA-12-020-EN.PDF. 
Evans, C.L. and Marshall, D.A. (2007). Economic determinants of the nominal treasury yield curve, Journal of Monetary Economics, 54(7), pp. 1986-2003.

Fabozzi, F.J. (2013). Bond markets, analysis, and strategies (8 ${ }^{\text {th }}$ ed.), Pearson Education, Essex.

Fama, E.J. (1984). The information in the term structure, Journal of Financial Economics, 13(4), pp. 509-528.

Fama, E.J. and Bliss, R.R. (1987). The information in long maturity forward rates, American Economic Review, 77(4), pp. 680-692.

Fendel, R. (2004). Towards a joint characterization of monetary policy and the dynamics of the term structure of interest rates. Deutsche Bundesbank Discussion Paper 24. Retrieved from http://www.econstor.eu/handle/ 10419/19491. $\square$

Fisher, I. (1886). Appreciation and interest, Publications of the American Economic Association, 11, pp. 23-92.

Fischer, I. (1930). Theory of interest, Macmillan, New York, NY.

Fischer, B., Lenza, M., Pill, H. and Reichlin, L. (2006). Money and monetary policy: The ECB experience 1999-2006. Paper presented at the $4^{\text {th }}$ ECB Central Banking Conference November 10-11, 2006. Retrieved from https://www.ecb.europa.eu/events/pdf/conferences/cbc4/ReichlinPillLenzaFisher.pdf. $\square$

Fitton, P. and McNatt, J.F. (2002). The four face of an interest rate model. In F. J. Fabozzi (Ed.), Interest rate, term structure and valuation modeling (pp. 27-38). John Wiley \& Sons, Hoboken, NJ.

Gali, J. (2010). The monetary pillar and the great financial crisis. In European Central Bank (Ed.), The great financial crisis: Lessons for financial stability and monetary policy, pp. 74-96, ECB, Frankfurt am Main. Retrieved from http://www.ecb.europa.eu/pub/pdf/other/greatfinancialcrisisecbcolloquiumpapademos201203en.pdf?092ffe72d8 7b184284180e8c011b12ff.

Gerdesmeier, D. and Roffia, B. (2003). Empirical estimates of the reaction functions for the euro area, ECB Working Paper 206. Retrieved from http://www.ecb.europa.eu/pub/pdf/scpwps/ecbwp206.pdf. $\square$

Gerlach, S. (2004). The two pillars of the ECB, Paper presented at the $39^{\text {th }}$ Panel Meeting of Economic Policy in Dublin on April 16-17, 2004. Retrieved from http://stefangerlach.com/EP.pdf.

Gerlach, S. and Svensson, L. (2003). Money and inflation in the euro area: A case for monetary indicators?, Journal of Monetary Economics, 50(8), pp. 1649-1672.

Geiger, F. (2011). The yield curve and financial risk premia, Lecture notes in Economics and Mathematical Systems 654, Springer-Verlag, Berlin.

Gourieroux, C. and Sufana, R. (2006). A classification of two-factor affine diffusion term structure models, Journal of Financial Econometrics, 4(1), pp. 31-52.

Hicks, J. (1939). Value and capital, Oxford University Press, London.

Hofmann, B. (2008). Do monetary indicators lead euro area inflation?, ECB Working Paper 867. Retrieved from http://www.ecb.europa.eu/pub/pdf/scpwps/ecbwp867.pdf.

Homer, S. and Sylla, R. (1996). A history of interest rates (3rd ed.), Rutgers University Press, New Brunswick, NJ.

Hördahl, P., Tristani, O. and Vestin, D. (2006). A joint econometric model of macroeconomic and term structure dynamics, Journal of Econometrics, 131(1), pp. 405-444. 
Ingersoll, J. (1987). Theory of financial decision making, Rowman \& Littlefield, Totowa, NJ.

Jakas, V. (2011). Theory and empirics of an affine term structure model applied to European data, AESTIMATIO, the IEB International Journal of Finance, 2, pp. 116-135. $\square$

- Jakas, V. (2012). Discrete Affine Term Structure Models Applied to German and Greek Government Bonds, AESTIMATIO, the IEB International Journal of Finance, 5, pp. 58-87.

Kessel, R.A. (1965). The cyclical behavior of the term structure of interest rates, NBER Books. Retrieved from http://papers.nber.org/books/kess65-1/. $\square$

Klöckers, H.J. and Willeke, C. (Eds.) (2001). Monetary analysis: Tools and applications, ECB, Frankfurt am Main. Retrieved from http://www.ecb.europa.eu/events/pdf/conferences/ecbmonetaryanalysis.pdf. $\square$

Langetieg, T.C. (1980). A multivariate model of the term structure, Journal of Finance, 35(1), pp. 71-97.

Lemke, W. (2008). An affine macro-finance term structure model for the euro area, The North-American Journal of Economics and Finance, 19(1), pp. 41-69.

- Litterman, R.B. and Scheinkman, J. (1991). Common factors affecting bond returns, The Journal of Fixed Income, $\mathbf{1}(1)$, pp. 54-61.

- Livingston, M. (1990). Money and capital markets: Financial instruments and their uses, Prentice-Hall, Englewood Cliffs, NJ.

- Longstaff, F.A. and Schwartz, E.S. (1992). Interest rate volatility and the term structure: a two-factor general equilibrium model, Journal of Finance, 47(4), pp. 1259-1282.

Lucas, R. (1978). Asset prices in an exchange economy, Econometrica, 46(6), pp. 1429-1454.

Lutz, F.A. (1940). The structure of interest rates, Quarterly Journal of Economics, 55(1), pp. 36-63.

Malkiel, B. (1966). The term structure of interest rates: Expectations and behavior patterns, Princeton University Press, Princeton, NJ.

Melino, A. (1986). The term structure of interest rates: Evidence and theory, NBER Working Paper 1828. Retrieved from http://www.nber.org/papers/w1828/. $\square$

Milyutin, A. (2014). Improving Mortgage Market Funding - Mortgage Covered Bonds, The $6^{\text {th }}$ Global Housing Finance Conference May 28-29, 2014, The World Bank Group. Retrieved from: http://siteresources.worldbank.org/ EXTFINANCIALSECTOR/Resources/282884-1337644231800/Housing_Finance_Mortgate_Covered_Bond.pdf. $\square$

Modigliani, F. and Sutch, R. (1966). Innovations in interest rate policy, American Economic Review, 56(1/2), pp. 178-197.

Nowalkha, S.K., Beliaeva, N.A. and Soto, G.M. (2007). Dynamic term structure modeling: The fixed income valuation course, John Wiley \& Sons, Hoboken, NJ.

Pearson, N.D. and Sun, T.S. (1993). An empirical examination of the Cox, Ingersoll and Ross model of the term structure of interest rates using the method of maximum likelihood, Journal of Finance, 54, pp. 929-959.

Piazzesi, M. (2005). Bond yields and the Federal Reserve, Journal of Political Economy, 113(2), pp. 311-344.

Piazzesi, M. (2010). Affine term structure models. In Y. Aït-Sahalia and L.P. Hansen (Eds), Handbook of financial econometrics: Tools and techniques, pp. 691-766, Elsevier B.V./North-Holland, Amsterdam. 
Piazzesi, M. and Schneider, M. (2006). Equilibrium yield curves, NBER Working Paper 12609. Retrieved from http://www.nber.org/papers/w12609/.

Roll, R. (1970). The behavior of interest rates: An application of the efficient market model to U.S. treasury bills, Basic Books, New York, NY.

Rubinstein, M. (1976). The valuation of uncertain income streams and the pricing of options, Bell Journal of Economics, 7(2), pp. 407-425.

Schaefer, S.M. and Schwartz, E.S. (1984). A two-factor model of the term structure: an approximate analytic solution, Journal of Financial and Quantitative Analysis, 19(4), pp. 413-424.

Schwarcz, S.L. (2011). The conundrum of covered bonds, The Business Lawyer, 66, pp. 561-586.

Shiller, R.J. and McCulloch, J.H. (1987). The term structure of interest rates, NBER Working Paper 2341. Retrieved from http://www.nber.org/papers/w2341/.

Spangler, M. and Werner, R. (2014). German covered bonds: Overview and risk analysis of Pfandbriefe, Springer Briefs in Finance, Springer International Publishing. Retrieved from: http://link.springer.com/chapter/10.1007/9783-319-02553-7_1\#page-1.

Stambaugh, R.F. (1988). The information in forward rates: Implications for models of the term structure, Journal of Financial Economics, 21(1), pp. 44-69.

Svensson, L.E.O. (1994). Estimating and interpreting forward interest rates: Sweden 1992-4, CEPR Discussion Paper Series 1051. Retrieved from http://www.cepr.org/pubs/dps/DP1051.asp.

Svensson, L.E.O. (2000). The first year of the Eurosystem: Inflation targeting or not?, NBER Working Paper 7598. Retrieved from http://www.nber.org/papers/w7598.

Taylor, J.B. (1993). Discretion versus policy rules in practice, Carnegie-Rochester Conference Series on Public Policy, 39, pp. 195-214.

Trecroci, C. and Vega, J.L. (2002). The information content of M3 for future inflation, Welfwirtschafliches Archiv, 138(1), pp. 22-53.

Tuckman, B. and Serrat, A. (2012). Fixed income securities: Tools for today's markets ( $3^{\text {rd }}$ ed.), John Wiley \& Sons, Hoboken, NJ.

Vasicek, O.A. (1977). An equilibrium characterization of the term structure, Journal of Financial Econometrics, 5(2), pp. 177-188.

Williams, J.B. (1938). The theory of investment value, Harvard University Press, Cambridge, Mass. 


\section{APPENDIX}

PEX Bloomberg German covered bonds yields data. state-space. Model with M3 Ann. Growth rates as in equations. (1) and (2)

\begin{tabular}{|c|c|c|c|c|c|c|c|c|c|c|c|c|c|c|c|}
\hline & EONIA & $\begin{array}{r}\text { Euribor } \\
3 \mathrm{M}\end{array}$ & $\begin{array}{r}\text { Euribor } \\
6 \mathrm{M}\end{array}$ & Y1 & Y2 & Y3 & Y4 & Y5 & Y6 & Y7 & Y8 & Y9 & Y10 & Y15 & Y2O \\
\hline & Coeff. & Coeff. & Coeff. & Coeff. & Coeff. & Coeff. & Coeff. & Coeff. & Coeff. & Coeff. & Coeff. & Coeff. & Coeff. & Coeff. & Coeff. \\
\hline & SE & SE & SE & SE & SE & SE & SE & SE & SE & SE & SE & SE & SE & SE & SE \\
\hline & t-stat & $t$-stat & t-stat & t-stat & $t$-stat & t-stat & t-stat & t-stat & t-stat & t-stat & t-stat & $t$-stat & t-stat & t-stat & t-stat \\
\hline \multirow[t]{3}{*}{ Intercept } & 16.42 & 5.39 & 1.86 & 12.18 & 20.27 & 24.82 & 27.08 & 27.52 & 28.22 & 28.68 & 29.21 & 29.34 & 29.29 & 30.73 & 33.96 \\
\hline & 1.75 & 1.94 & 1.87 & 1.59 & 1.72 & 1.94 & 2.06 & 2.14 & 2.18 & 2.20 & 2.22 & 2.23 & 2.25 & 2.39 & 2.45 \\
\hline & 9.41 & 2.78 & 0.99 & 7.64 & 11.76 & 12.81 & 13.12 & 12.83 & 12.96 & 13.05 & 13.16 & 13.15 & 13.01 & 12.88 & 13.85 \\
\hline \multirow[t]{3}{*}{$\log C C I$} & 0.08 & 0.05 & 0.05 & 0.06 & 0.03 & 0.01 & 0.00 & -0.01 & -0.02 & -0.03 & -0.03 & -0.04 & -0.04 & -0.04 & -0.04 \\
\hline & 0.03 & 0.01 & 0.01 & 0.02 & 0.02 & 0.01 & 0.01 & 0.01 & 0.01 & 0.01 & 0.01 & 0.02 & 0.02 & 0.02 & 0.0 \\
\hline & 3.22 & 4.40 & 4.25 & 2.76 & 1.99 & 1.02 & -0.48 & -2.29 & -2.59 & -2.60 & -2.61 & -2.64 & -2.57 & -2.74 & -2.92 \\
\hline \multirow[t]{3}{*}{ Log Unemployment } & -8.65 & -9.67 & -9.45 & -9.71 & -8.79 & -8.17 & -7.56 & -6.91 & -6.42 & -5.99 & -5.66 & -5.39 & -5.16 & -4.70 & -4.47 \\
\hline & 0.27 & 0.30 & 0.30 & 0.33 & 0.36 & 0.37 & 0.36 & 0.35 & 0.34 & 0.33 & 0.32 & 0.31 & 0.31 & 0.31 & 0.3 \\
\hline & -32.16 & -32.68 & -31.49 & -29.47 & -24.65 & -22.27 & -20.78 & -19.50 & -18.86 & -18.22 & -17.64 & -17.11 & -16.56 & -15.33 & -14.52 \\
\hline \multirow[t]{3}{*}{ Log M3 ann. growth } & 0.27 & 0.25 & 0.21 & 0.19 & 0.12 & 0.05 & -0.01 & -0.04 & -0.06 & -0.07 & -0.08 & -0.09 & -0.09 & -0.14 & -0.14 \\
\hline & 0.03 & 0.02 & 0.02 & 0.02 & 0.02 & 0.02 & 0.03 & 0.03 & 0.03 & 0.03 & 0.03 & 0.03 & 0.03 & 0.04 & 0.0 \\
\hline & 10.22 & 11.92 & 11.78 & 9.60 & 7.34 & 2.01 & -0.50 & -1.27 & -1.79 & -2.16 & -2.51 & -2.67 & -2.80 & -3.91 & -3.6 \\
\hline \multirow[t]{3}{*}{ Log PPI } & 0.87 & 3.88 & 4.59 & 2.46 & 0.33 & -0.88 & -1.60 & -1.96 & -2.31 & -2.58 & -2.82 & -2.96 & -3.04 & -3.51 & -4.3 \\
\hline & 0.39 & 0.47 & 0.47 & 0.44 & 0.49 & 0.51 & 0.52 & 0.52 & 0.52 & 0.52 & 0.52 & 0.52 & 0.52 & 0.55 & 0.5 \\
\hline & 2.25 & 8.29 & 9.87 & 5.53 & 0.67 & -1.73 & -3.09 & -3.76 & -4.44 & -4.97 & -5.42 & -5.70 & -5.83 & -6.42 & -7.70 \\
\hline 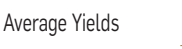 & 1.94 & 2.31 & 2.46 & 2.44 & 2.65 & 2.86 & 3.05 & 3.22 & 3.36 & 3.48 & 3.59 & 3.68 & 3.76 & 4.01 & 4. \\
\hline . & 1.34 & 1.39 & 1.33 & 1.36 & 1.22 & 1.11 & 1.00 & 0.91 & 0.85 & 0.80 & 0.77 & 0.74 & 0.71 & 0.66 & 0.0 \\
\hline Jarque Bera Test & 33.59 & 11.81 & 11.57 & 14.35 & 9.88 & 5.11 & 2.38 & 2.30 & 3.22 & 4.36 & 5.29 & 5.89 & 6.36 & 8.04 & 8.5 \\
\hline $2^{2}$ & 0.95 & 0.96 & 0.96 & 0.96 & 0.95 & 0.93 & 0.91 & 0.89 & 0.87 & 0.85 & 0.83 & 0.82 & 0.80 & 0.75 & 0.75 \\
\hline $\mathrm{R}^{2}$ Adjusted & 95 & 0.96 & 0.95 & 0.96 & 95 & 0.93 & 0.91 & 0.89 & 0.87 & 0.85 & 0.83 & 0.81 & 0.79 & 0.74 & 0.74 \\
\hline DW Statistic & 0.59 & 0.42 & 0.43 & 0.56 & 0.50 & 0.44 & 0.38 & 0.35 & 0.32 & 0.31 & 0.30 & 0.30 & 0.31 & 0.28 & 0.27 \\
\hline Test for ARCH effects & 56.79 & 38.01 & 42.88 & 40.02 & 33.78 & 34.01 & 34.30 & 35.01 & 36.64 & 39.10 & 42.41 & 44.51 & 46.13 & 50.83 & 50.14 \\
\hline
\end{tabular}

Data: pex bloomberg, monthly average. observations: 107. period: november 2003 - september 20I2. estimation method: state-space. 